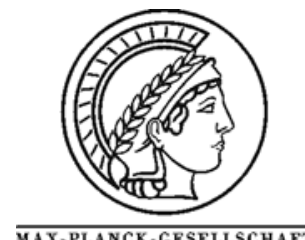

Originally published as:

"Kinetics of ammonia oxidation over Pt foil studied in a micro-structured quartz-reactor" Ralph Kraehnert, Manfred Baerns

Chemical Engineering Journal 137 (2008) 361-375

doi:10.1016/j.cej.2007.05.005 


\title{
Kinetics of ammonia oxidation over Pt foil studied in a micro-structured quartz-reactor
}

\author{
Ralph Kraehnert*, Manfred Baerns ${ }^{1}$ \\ Leibniz-Institute for Catalysis at the University of Rostock, Branch Berlin (former ACA), \\ Richard-Willstaetter-Str. 12, D-12489 Berlin, Germany
}

Received 20 October 2006; received in revised form 27 April 2007; accepted 2 May 2007

\begin{abstract}
The kinetics of Pt-catalyzed ammonia oxidation on polycrystalline Pt were investigated at partial pressures of ammonia and oxygen up to $6 \mathrm{kPa}$ and temperatures between 286 and $385^{\circ} \mathrm{C}$, applying a micro-structured reactor that ascertained temperature control of the exothermic reaction. Using literature-based mechanistic models, a micro-kinetic model was derived based on parameter optimization and a model discrimination procedure. The model described the rates of formation of all nitrogen-containing products, i.e. $\mathrm{N}_{2}, \mathrm{~N}_{2} \mathrm{O}$ and NO . Catalyst characterization of platinum samples by electron microscopy indicated that reaction-induced restructuring of the Pt surface limited the accuracy of derived kinetic parameters already at the low temperature applied in this work. Despite of necessary simplifications, the best-fitting kinetic model predicted reasonable product selectivities for the reaction conditions of an industrial ammonia burner.
\end{abstract}

(C) 2007 Elsevier B.V. All rights reserved.

Keywords: Catalytic ammonia oxidation; Platinum catalyst; Kinetics; Micro-structured reactor

\section{Introduction}

The selective oxidation of ammonia to NO over Pt-containing alloy gauzes is applied in the industrial production of nitric acid. While nitric oxide is the main product of ammonia oxidation at high temperatures $\left(>500^{\circ} \mathrm{C}\right), \mathrm{N}_{2}$ formation dominates below ca. $300^{\circ} \mathrm{C}$. Depending on pressure $(>10 \mathrm{~Pa})$, small amounts of nitrous oxide are formed as byproduct. The kinetics of Ptcatalyzed ammonia oxidation are complex and were studied repeatedly, but a common understanding has not been reached yet, also due to experimental difficulties.

The difficulties in studying ammonia oxidation experimentally arise from the fact that the reaction is fast, highly exothermic and induces restructuring of the catalyst surface. Accordingly, problems were encountered with respect to mass and heat transfer, and hence, with temperature control (ignition on $\mathrm{Pt}$ black, $\mathrm{Pt} / \mathrm{Al}_{2} \mathrm{O}_{3}$ [1] and Pt wire [2,3]). Different solutions for temperature-control were proposed and implemented:

\footnotetext{
* Corresponding author. Tel.: +49 306392 4438; fax: +49 3063924454.

E-mail address: ralph.kraehnert@ catalysis.de (R. Kraehnert).

${ }^{1}$ Present address: Fritz-Haber-Institut, Faradayweg 4-6, 14195 Berlin, Germany.
}

(a) reducing the reaction rate by decreasing reactant pressure,

(b) reducing the reaction rate by decreasing temperature

(c) improving heat transfer applying micro-structured reactors.

(a) Decreasing the partial pressure of reactants lowers reaction rates, resulting in lower heat generation on the catalyst surface. The drawback is that no information on $\mathrm{N}_{2} \mathrm{O}$ formation can be derived in such experiments, since nitrous oxide was not detected in most studies carried out in ultra-high vacuum. Hence, kinetic models derived from low-pressure measurements were often limited to simplified explicit rate expressions for the rate of $\mathrm{NO}$ formation [4,5], or of $\mathrm{N}_{2}$ and $\mathrm{NO}$ formation [2,6,7]. Recently, Scheibe et al. developed a micro-kinetic model based on available mechanistic information and rate measurements over stepped $\mathrm{Pt}$ single crystals at pressures below $10^{-2} \mathrm{~Pa}$ [8-10], but they also accounted only for rates of $\mathrm{NO}$ and $\mathrm{N}_{2}$ formation.

(b) The second approach for solving the problem of temperature control in the catalytic ammonia oxidation is a decrease of reaction temperature while keeping partial pressures in the $\mathrm{kPa}$ range; hereby reaction rates are reduced, and hence also the heat generation on the catalyst surface. Respective studies were limited to temperatures below $300^{\circ} \mathrm{C}[1,11-13]$, and therefore no 


\begin{tabular}{|ll|}
\hline Nomenclature \\
$a, b$ & different types of adsorption sites \\
$A$ & surface area \\
$c_{i}$ & concentration (volume fraction) of component $i$ \\
& in the gas phase \\
$E_{\mathrm{A}}$ & activation energy \\
$k_{j}$ & kinetic constant of reaction $j$ \\
$n$ & reaction order \\
$\dot{n}_{i}$ & molar flow rate \\
$p$ & pressure \\
$R$ & universal gas constant \\
$r_{j}$ & rate of reaction step $j$ \\
$R_{i}$ & rate of formation or consumption of component $i$ \\
$S_{i}$ & selectivity of product $i$ \\
$T$ & temperature \\
$\dot{V}$ & volumetric flow rate \\
$w(T, i)$ & weighting factor for component $i$ at temperature \\
& $T$ \\
$G r e k$ & \\
$\Theta_{i}$ & letters \\
$v$ & surface coverage by component $i$ \\
&
\end{tabular}

information on the formation of the high-temperature product NO has been obtained. Thus, corresponding kinetic models described only the rate of formation of $\mathrm{N}_{2}$ and $\mathrm{N}_{2} \mathrm{O}$ (Pt black and $\mathrm{Pt} / \mathrm{Al}_{2} \mathrm{O}_{3}$ [1,13]; Pt wire: $[11,12])$.

(c) Rebrov et al. extended the range of temperaturecontrolled ammonia oxidation near atmospheric pressure to $360^{\circ} \mathrm{C}$ applying micro-structured reactors ([14-16]), which are known for their inherently good heat removal. The authors tested different reactors [14] and measured ammonia conversion and product selectivity at various temperatures $[15,16]$. Based on the data and on assumed elementary reaction steps from literature for model systems, a micro-kinetic model was proposed for ammonia oxidation on alumina-supported Pt.

The literature presented above shows that the best way to assure temperature control in catalytic ammonia oxidation is the application of micro-structured reactors. Moreover, only two micro-kinetic models have been published so far for Ptcatalyzed ammonia oxidation by Scheibe et al. [9,10] $(\operatorname{Pt}(533))$ and Rebrov et al. $[15,16]\left(\mathrm{Pt} / \mathrm{Al}_{2} \mathrm{O}_{3}\right)$, but a comprehensive model for the poly-crystalline materials relevant for industrial application does not exist. The two published models are assessed in detail below.

Scheibe [8] and Scheibe et al. [9] investigated ammonia oxidation over $\operatorname{Pt}(533)$ and $\operatorname{Pt}(443)$ at pressures of $10^{-3}$ to $10^{-2} \mathrm{~Pa}$ in a differential reactor. The rates of $\mathrm{NO}$ and $\mathrm{N}_{2}$ formation were recorded in temperature-programmed ammonia oxidation $\left(150-700^{\circ} \mathrm{C}\right)$, and during partial pressure variation at
$250-350{ }^{\circ} \mathrm{C}$. One micro-kinetic model was proposed and fitted to the steady-state data [10]. The model contained 11 elementary reactions and one lumped reaction step describing activation of the adsorbed ammonia molecules by atomic oxygen. The lumping of the ammonia activation step was rationalized by a lack of information on the kinetics of stepwise $\mathrm{NH}_{x}$ dehydrogenation. The model described the influence of temperature on the rates of formation of $\mathrm{NO}$ and $\mathrm{N}_{2}$ well, but the influence of feed composition was not equally well captured. Due to the low pressure and a differential reactor, the model neither described the formation of $\mathrm{N}_{2} \mathrm{O}$, nor the influence of secondary reactions. Moreover, experimentally observed hysteresis behavior and surface restructuring were not accounted for [8].

Rebrov et al. presented the first kinetic study of ammonia oxidation that took into account the formation of $\mathrm{N}_{2}, \mathrm{~N}_{2} \mathrm{O}$ and $\mathrm{NO}$ $[15,16]$. Formation of these products was investigated between 240 and $360{ }^{\circ} \mathrm{C}$ and close to atmospheric pressure $[15,16]$. Ignition was avoided by using a micro-structured reactor made of aluminum plates [15], where the channel walls were converted to $\mathrm{Al}_{2} \mathrm{O}_{3}(\sim 25 \mu \mathrm{m})$ and loaded with $\mathrm{Pt}$ via impregnation. A mixture of ammonia and oxygen was fed to the reactor at different partial pressures and temperatures, and formation of $\mathrm{N}_{2}$ and $\mathrm{N}_{2} \mathrm{O}$ was followed by GC. Measurements were carried out at high conversion, i.e. complete ammonia conversion was reached around $300{ }^{\circ} \mathrm{C}$, the same temperature at which the onset of NO production was inferred from the nitrogen mass-balance. The kinetic model was developed based on earlier studies of kinetics and mechanism on Pt single crystals, assuming adsorption sites and reactions steps on supported $\mathrm{Pt} / \mathrm{Al}_{2} \mathrm{O}_{3}$ to be similar to those on a $\mathrm{Pt}(100)$ model surface. The better of two tested kinetic models described $\mathrm{NH}_{3}$ conversion, $\mathrm{N}_{2}$ selectivity and $\mathrm{N}_{2} \mathrm{O}$ selectivity using 12 elementary reaction steps and one lumped reaction of ammonia activation. The models ability to describe secondary reactions was limited to decomposition of $\mathrm{N}_{2} \mathrm{O}$, since re-adsorption of the product $\mathrm{NO}$ was excluded from the set of reactions. Moreover, although catalytic activity changed in the initial time-on-stream, the catalyst was not characterized after reaction. Hence, respective reaction-induced changes of the surface of $\mathrm{Pt} / \mathrm{Al}_{2} \mathrm{O}_{3}$ catalyst were not elucidated. Since Sobczyk [17] and van den Broek [18] reported that supported and non-supported $\mathrm{Pt}$ differ in activity and deactivation behavior in the low-temperature ammonia oxidation, the kinetic model for $\mathrm{Pt} / \mathrm{Al}_{2} \mathrm{O}_{3}$ is not necessarily valid for polycrystalline materials such as $\mathrm{Pt}$ gauzes.

As evidenced by the cited kinetic models of ammonia oxidation, kinetics do not exist so far for the technically relevant polycrystalline catalyst under conditions were all three nitrogencontaining products $\mathrm{NO}, \mathrm{N}_{2}$ and $\mathrm{NO}$ are formed. Moreover, studies for the reaction over single crystals $[9,10]$ and supported catalysts [16] are deficient: Problems were encountered to establish a defined steady state, and although reaction-induced changes of the Pt surface were presumed to be responsible, the surface of the catalyst was not characterized after kinetic measurements. Moreover, one model [10] did not describe formation of the product $\mathrm{N}_{2} \mathrm{O}$ nor secondary reactions, while the other study [16] had to refer to the nitrogen balance in order to estimate the amount of produced nitric oxide. 
The aim of the present investigation was to overcome the discussed limitations, and to develop a micro-kinetic model for ammonia oxidation on polycrystalline Pt. Reaction kinetics were studied under conditions where significant amounts of all the nitrogen-containing products $\mathrm{N}_{2}, \mathrm{~N}_{2} \mathrm{O}$ and $\mathrm{NO}$ are formed. Moreover, the relevance of secondary reactions was tested experimentally by adding reaction products to the feed of ammonia and oxygen. The experimental data were used to develop different micro-kinetic models at reactant partial pressures up to $6 \mathrm{kPa}$, from which the best-fitting model was identified via modeldiscrimination. In addition, the Pt surface was characterized before and after kinetic measurements to elucidate a possible influence of reaction-induced changes of the Pt surface on the measured kinetic data. Finally, the model was extrapolated to conditions of an industrial ammonia burner to verify computed selectivities against real values.

\section{Experimental}

Kinetics of catalytic ammonia oxidation were studied on samples of Pt foil mounted in a micro-structured quartz reactor. Section 2 of the present publication describes the catalyst (Section 2.1), the reactor (Section 2.2), the methodology of kinetic measurements, modeling and model discrimination (Section 2.3), and finally the catalyst characterization (Section 2.4).

\subsection{Catalyst}

Pt thin-foil with a purity of $99.95 \%$ supplied by Alfa Aesar (Ward Hill, MA, USA) was used as catalyst without any catalyst pretreatment. Nominal thickness of the foil amounted to $4 \mu \mathrm{m}$. Images of the fresh catalyst taken by scanning electron microscopy (Fig. 1) show a smooth surface with few small scratches and holes. XPS spectra (not shown) indicated that the surface of fresh Pt foil featured the expected peaks characteristic for platinum, carbon and oxygen species.

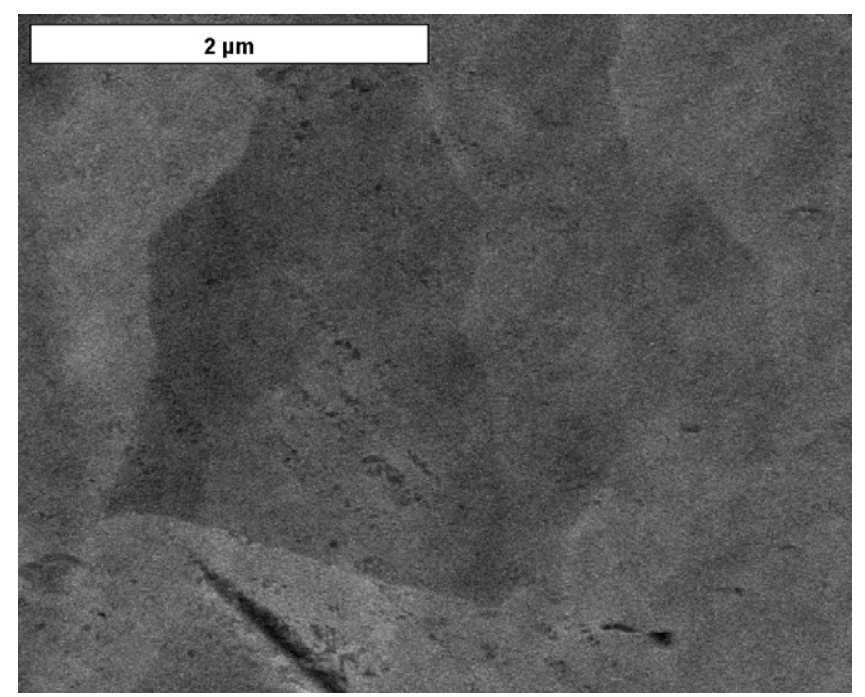

Fig. 1. SEM of fresh Pt foil catalyst, as supplied by Alfa Aesar.

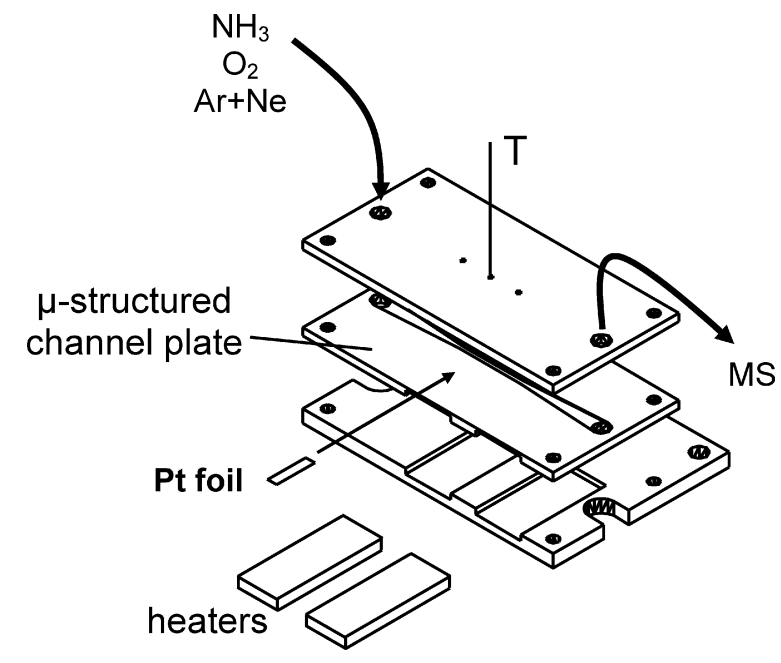

Fig. 2. Assembly of micro-structured quartz reactor and catalyst (Pt foil).

\subsection{Reactor}

The reactor applied in the kinetic measurements has been presented before in detail $[19,20]$. Briefly, the reactor shown in Fig. 2 consisted of a stack of quartz-plates, two heating elements, two thermocouples, and screws and clamps to achieve sealing. Two hollow screws were mounted via holes drilled through the stack to link gas supply and gas analytics to the reactor. The middle plate carried two micro-structured reaction-channels, each $500 \mu \mathrm{m}$ wide and $300 \mu \mathrm{m}$ deep. On the upper side of the channels, the catalyst Pt thin-foil was placed. Most of the surface of the foil samples was covered by the reactor wall. Hence, only two small areas of the foil were exposed to reactants with a surface area in the order of $2 \mathrm{~mm}^{2}(2 \times 500 \mu \mathrm{m} \times 2 \mathrm{~mm})$. The catalysts thickness $(4 \mu \mathrm{m})$ was negligible in comparison to the dimensions of reaction channels and the reactor. A top plate sealed the reaction channels and held the catalyst in position. The flat geometry offered the largest possible contact area between Pt foil and reactor wall, assuring optimal heat dissipation from the catalyst. Temperature was measured from the top plate with a thermocouple located less than $200 \mu \mathrm{m}$ from the back of the catalyst.

Premixed gases were continuously dosed to the reactor via electronic mass flow controllers for $\mathrm{NH}_{3}(99.8 \%), \mathrm{O}_{2}(99.98 \%)$, $\mathrm{Ar}(99.99 \%), \mathrm{Ne}(99.99 \%), \mathrm{NO}$ (9.76\% NO in $\mathrm{Ar}$ ) and $\mathrm{N}_{2} \mathrm{O}$ (99.996\%). Gas composition was analyzed every 10 s downstream of the reactor by QMS (Balzer Omnistar GCD 300). Intensities at atomic masses 2, 15, 17, 18, 20, 22, 28, 30, 32, 40, 44 and 46 were recorded and evaluated for quantification of $\mathrm{H}_{2}$, $\mathrm{NH}_{3}, \mathrm{H}_{2} \mathrm{O}, \mathrm{Ar}, \mathrm{Ne}, \mathrm{N}_{2}, \mathrm{NO}, \mathrm{O}_{2}, \mathrm{~N}_{2} \mathrm{O}$ and $\mathrm{NO}_{2}$, using $10 \%$ of $\mathrm{Ne}$ as internal standard. Rates (in $\mathrm{mol} \mathrm{m}^{-2} \mathrm{~s}^{-1}$ ) were derived from the differences in inlet and outlet flow $\left(c_{\mathrm{o}}-c_{\text {exit }}\right) \times \dot{V}$ assuming differential reactor operation, ideal gas law and negligible changes of volumetric flow rate:

$R_{i}=\Delta c_{i} \frac{p \dot{V}}{R T} \frac{1}{A_{\text {cat }}}$

Since the surface area $A_{\text {cat }}$ of the catalyst was too low to be measured by adsorption methods, the concentration changes 
were related to the surface area of flat Pt. The validity of assuming reactor operation in differential mode was assured by measuring kinetic data at conversions below $11 \%$, i.e. changes of concentration over the reactor were small. Blank activity of the reactor was negligible up to $700^{\circ} \mathrm{C}$. Moreover, the kinetic regime was verified for the actual reaction conditions by replacing the diluting gas $\mathrm{Ar}$ with $\mathrm{He}$, thus varying diffusion coefficients and hence, mass transfer coefficients [20]. Negligible deviation between reaction rates measured in $\mathrm{Ar}$ and He indicated prevalence of the kinetic regime up to $385^{\circ} \mathrm{C}$ [21]. The error of product quantification, estimated for temperatures of 286,330 , 374 and $385^{\circ} \mathrm{C}$ from replicate measurements, amounted to reasonable values between 4.4 and $13.4 \%$, depending on evaluated gas-phase species and reaction conditions.

\subsection{Methodology}

In the following sections, the methodology applied in the kinetic study is illustrated considering (1) design of experiments, (2) the experimental procedure, and (3) the kinetic modeling.

\subsubsection{Design of experiments}

Kinetic data were measured in the reactor operated in differential mode, applying a strategy proposed by Froment and Bishoff [22]: Interactions of "pure feed" $\left(\mathrm{NH}_{3}, \mathrm{O}_{2}\right)$ with the catalyst at low conversion were studied first, assuming that the resulting concentration of products in the gas phase is small. Thereafter, product interactions were investigated supplying "mixed feed" to the catalyst, i.e. pure feed $\left(\mathrm{NH}_{3}+\mathrm{O}_{2}\right)$ mixed with one of the reaction products $\left(\mathrm{N}_{2} \mathrm{O}, \mathrm{NO}\right)$.

The investigated parameters comprised the feed composition $\left(p_{\mathrm{NH}_{3}}, p_{\mathrm{O}_{2}}, p_{\mathrm{NO}}, p_{\mathrm{N}_{2} \mathrm{O}}\right)$ and temperature. Pure and mixed feeds were studied at temperatures of $286,330,374$ and $385^{\circ} \mathrm{C}$, where the upper temperature limit was imposed by mass-transfer limitation [21]. The reaction products nitric and nitrous oxide undergo secondary reactions, and were therefore included in the studies of mixed-feed. Since the dissociation of $\mathrm{N}_{2}$ is not catalyzed by platinum, and water was the only hydrogen-containing product observed, secondary reactions of both $\mathrm{N}_{2}$ and $\mathrm{H}_{2} \mathrm{O}$ were negligible. Moreover, recent kinetic studies reported negligible surface coverages for both species $[10,16]$ under reaction conditions.

In order to maximize the information contained in the kinetic data, experimental points were distributed according to standard designs-of-experiment [23]: Since nitrogen formation is favored in ammonia excess and NO production occurs only in oxygen excess, a wide range of ratios $\mathrm{NH}_{3}: \mathrm{O}_{2}$ was covered $\left(p_{\mathrm{NH}_{3}}: p_{\mathrm{O}_{2}}=1: 6\right.$ to $6: 1$ ), combining a three-level full factorial design with mono-variant responses around a central point $\left(p_{\mathrm{NH}_{3}}: p_{\mathrm{O}_{2}}=3: 3 \mathrm{kPa}\right)$. Replicate measurements were carried out at the corners of the chosen parameter space to provide a balanced estimate of the experimental error variance for all three nitrogen-containing products $\mathrm{N}_{2}, \mathrm{~N}_{2} \mathrm{O}$ and $\mathrm{NO}$ [24].

The influence of adding the reaction products $\mathrm{NO}$ and $\mathrm{N}_{2} \mathrm{O}$ to the feed containing ammonia and oxygen was studied with an experimental design similar to a Box-Behnken design, re-using already measured points of pure feed $\left(p_{\mathrm{NO}}=p_{\mathrm{N}_{2} \mathrm{O}}=0 \mathrm{kPa}\right)$.
Additional points were recorded for concentrations of NO and $\mathrm{N}_{2} \mathrm{O}$ up to $0.47 \mathrm{kPa}$, i.e. product concentrations that would correspond to an ammonia conversion of up to $96 \%$ for the conditions of the present experiments. A possible interaction between $\mathrm{NO}$ and $\mathrm{N}_{2} \mathrm{O}$ was neglected. In total, 108 distinct sets of rate data were measured to assess the influence of five experimental variables $\left(p_{\mathrm{NH}_{3}}, p_{\mathrm{O}_{2}}, p_{\mathrm{NO}}, p_{\mathrm{N}_{2} \mathrm{O}}\right.$ and $\left.T\right)$ on three model responses ( $R_{\mathrm{N}_{2}}, R_{\mathrm{NO}}, R_{\mathrm{N}_{2} \mathrm{O}}$ ). (A complete list of the experimental conditions and kinetic data is available online [21].)

\subsubsection{Experimental procedure}

Steady-state kinetics of catalytic ammonia oxidation were measured on four different samples of Pt foil, starting with a fresh catalyst sample at each investigated temperature. Initially, the reactor was flushed at room temperature, followed by admission of a standard feed mixture $\left(250 \mathrm{ml} / \mathrm{min} \mathrm{STP;} 3 \mathrm{kPa} \mathrm{NH}_{3}\right.$, $4.5 \mathrm{kPa} \mathrm{O}_{2}$ ) to the bypass. Thereafter, the feed gas was switched to the reactor. The reactor was then heated to the desired temperature level in order to equilibrate the fresh catalyst to reaction conditions for $14 \mathrm{~h}$ time-on-stream, where an initial period of catalyst activation was observed. After reaching stable activity, product gas composition was recorded at the various conditions given by the experimental design in the order "pure feed", influence of contact time (to verify differential reactor operation), replicate runs (for error estimates), and "mixed feed" (see [21] for complete data). Product composition was measured for at least 15 min at each condition: concentrations were usually constant after $5 \mathrm{~min}$. At the end of each experiment the standard feed mixture was re-measured at reaction temperature and in bypass to test for further catalyst activation and QMS drift, respectively. Values for the overall change in activity during acquisition of kinetic data were about $11 \%$, hence steady-state can be assumed. Temperature and pressure were held constant throughout each experiment.

\subsubsection{Kinetic modeling}

Using mechanistic and kinetic information available in literature, elementary reaction steps were proposed to account for the reaction paths, and the respective kinetic equations were deduced. Three kinetic models as listed in Section 4 were tested, which were based on published kinetic studies of Scheibe et al. $[9,10]$ and Rebrov et al. [16], as well as an improved model suggested by the present authors. The parameters of each model were adjusted to minimize the deviation between measured and simulated rate data at all four temperatures, using 52 different sets of rate data for the $\mathrm{NH}_{3}-\mathrm{O}_{2}$ interaction, and additional 28 data sets for the $\mathrm{NH}_{3}-\mathrm{O}_{2}-\mathrm{NO}$ interactions. Thereafter, the models were discriminated by their ability to describe the kinetic data qualitatively and quantitatively (via $F$-test).

For kinetic modeling and optimization of kinetic parameters, a Fortran program and a strategy reported by Wolf and Moros [25] were applied. Briefly summarized, a so-called genetic algorithm searched for the global minimum of a residual function by systematically varying the values for kinetic pre-factors and activation energies in a constrained meaningful range. The initial solutions derived from the genetic algorithm were then further refined applying the gradientless Nelder-Mead method [26] that 
shows better performance in the near-optimum region [25].

To reduce the correlation between activation energies and pre-exponential terms, the temperatures were centered around an intermediate reference temperature, $T_{\text {ref }}$, of $385^{\circ} \mathrm{C}$ [27]:

$k_{j}(T)=k_{j}\left(T_{\text {ref }}\right) \exp \left[-\frac{E_{\mathrm{A}, j}}{R}\left(\frac{1}{T}-\frac{1}{T_{\text {ref }}}\right)\right]$

The rate expressions for all reaction steps are given by a set of equations

$r_{j}=k_{j} \prod_{i} p_{i}^{n_{i, j}} \prod_{k} \Theta_{k}^{n_{k, j}}, \quad$ where $\frac{\mathrm{d} \Theta_{k}}{\mathrm{~d} t}=\sum_{j} v_{k, j} r_{j} \stackrel{!}{\longrightarrow} 0$

with $\Theta_{k}$ surface coverage of species $k, r_{j}$ the rate of reaction $j$, $v_{k, j}$ the stoichiometric coefficient of species $k$ in reaction $j, p_{i}$ the partial pressure of species $i$ and $n_{k, j}$ as the reaction order with respect to species $k$ in reaction $j$, from which the experimentally observable rates of product formation of a gas-phase species $i$, $R_{i}$, were computed as the difference between the respective rates of desorption and adsorption of a product species

$R_{i}=r_{i, \text { desorption }}-r_{i, \text { adsorption }}$

The residual function ("RESF") which was minimized during the search for optimized kinetic constants was computed from the sum of squared deviations of the rates of product formation, $R_{i}$, corrected by weights w that account for the different total amounts of each product formed at different temperatures [23]:

$\mathrm{RESF}=\sum_{n} \sum_{i}\left(R_{i, n, \exp }-R_{i, n, \operatorname{sim}}\right)^{2} w\left(T_{n}, i\right)$

with $n$ is the number of the measurement, $i$ the chemical species $i$ and $w$ as the weights.

The optimization algorithm was implemented in Fortran 77 with Compaq Visual FORTRAN 6.6. Code for the genetic algorithm, written by Wolf and Moros [25], for the Nelder-Mead algorithm from Numerical Recipies [28], and the integration routine D02HBF from the Numerical Algorithm Group (NAG) [29] were used. Steady-state coverages of the surface were computed numerically.

The best-fitting solution of each model was considered in the model discrimination procedure. First, models that did not describe the experimentally observed trends were discarded. The remaining models were compared to each other based on their lack-of-fit. Moreover, to evaluate if the respective differences in modeling quality were significant, models were also compared applying an $F$-test on a confidence level of $(1-\alpha)=99 \%$ (Table 4).

\subsection{Catalyst characterization}

The surface morphology of Pt catalyst was studied by scanning electron microscopy (SEM). Images were recorded on a Hitachi-S4000 equipped with FEG (cold) in SE mode. An energy-dispersive analyzer (DX 4, EDAX Inc.) equipped with Li-doped Si crystals was attached to the SEM for element analysis (EDX). Electron accelerating voltage for images and spectra was $15 \mathrm{kV}$.

\section{Steady-state kinetic data: influence of reaction conditions on rates of product formation}

The experimental results of kinetic measurements are presented with respect to how the rates of formation of $\mathrm{N}_{2}, \mathrm{~N}_{2} \mathrm{O}$ and NO were influenced by (1) temperature, (2) the feed composition, i.e. the partial pressures of oxygen and ammonia, and (3) the amounts of $\mathrm{NO}$ and $\mathrm{N}_{2} \mathrm{O}$ added to a feed containing oxygen and ammonia.

\subsection{Effect of temperature on reaction rates}

The influence of temperature on the rate of formation of $\mathrm{N}_{2}$, $\mathrm{N}_{2} \mathrm{O}$ and $\mathrm{NO}$ is shown in Fig. $3 \mathrm{~d}$ for the case of oxygen excess; in ammonia excess nitrogen is formed almost exclusively. The main reaction product was $\mathrm{N}_{2}$ (Fig. $3 \mathrm{~d}$ ), with an increasing rate of formation at higher temperatures. A second product detected in the whole temperature range was nitrous oxide. Finally, production of NO was observed only above $330^{\circ} \mathrm{C}$. Formation of all products increased with temperature, with the increase in formation of $\mathrm{N}_{2}$ and $\mathrm{N}_{2} \mathrm{O}$ leveling off at the maximum temperature in favor of higher NO production.

The observed influence of temperature on product distribution agrees well with published data for other Pt catalysts and pressure ranges; nitrogen was previously reported to be the main product at low temperatures in ammonia excess, and a maximum for the rate of $\mathrm{N}_{2}$ formation was found at $200-400^{\circ} \mathrm{C}$, depending on the pressure $[19,30,31]$. Moreover, the side product $\mathrm{N}_{2} \mathrm{O}$ was reported to be formed at pressures above 6-160 Pa [19,32], with an expected maximum for the rate of $\mathrm{N}_{2} \mathrm{O}$ formation around $300-500{ }^{\circ} \mathrm{C}[16,19,33]$. NO production was previously found to start at ca. $200-300{ }^{\circ} \mathrm{C}$ (depending on pressure), and to increase with temperature $[16,19,30,31]$. The observation of NO formation only above $330^{\circ} \mathrm{C}$ allows to dividing the present experimental data for further discussion into a high-temperature reaction regime with formation of $\mathrm{NO}\left(374,385^{\circ} \mathrm{C}\right)$, and a lowtemperature regime with exclusive $\mathrm{N}_{2}$ and $\mathrm{N}_{2} \mathrm{O}$ production (286, $\left.330^{\circ} \mathrm{C}\right)$.

\subsection{Partial pressure of oxygen and ammonia}

The influence of the partial pressures of oxygen and ammonia on the rates of formation of $\mathrm{N}_{2}, \mathrm{~N}_{2} \mathrm{O}$ and $\mathrm{NO}$ is illustrated in Fig. $3 \mathrm{a}-\mathrm{c}$ for $385^{\circ} \mathrm{C}$, i.e. representative for the temperature regime where NO is formed as a product. The rate of $\mathrm{N}_{2}$ formation increased with partial pressures of ammonia as well as oxygen (Fig. 3a). In excess of one component, the $\mathrm{N}_{2}$ production reached a constant value, either at the maximum level or slightly below (e.g. Fig. $3 \mathrm{a}\left\{p_{\mathrm{NH}_{3}}=1 \mathrm{kPa}, p_{\mathrm{O}_{2}}=1-6 \mathrm{kPa}\right\}$ and $\left.\left\{p_{\mathrm{O}_{2}}=1 \mathrm{kPa}, p_{\mathrm{NH}_{3}}=1-6 \mathrm{kPa}\right\}\right)$. In contrast, $\mathrm{N}_{2} \mathrm{O}$ production increased with the oxygen content of the feed, but decreased in ammonia excess. The initial increase of $R_{\mathrm{N}_{2} \mathrm{O}}$ with $p_{\mathrm{O}_{2}}$ was almost linear, but the slope of the respective curves decreased in larger oxygen excess (Fig. 3b). Production of significant amounts of NO required excess of oxygen (Fig. 3c). Accordingly, $\mathrm{NO}$ formation increased with the $\mathrm{O}_{2}$ to $\mathrm{NH}_{3}$ ratio, with an almost linear dependence on the oxygen partial pressure in 

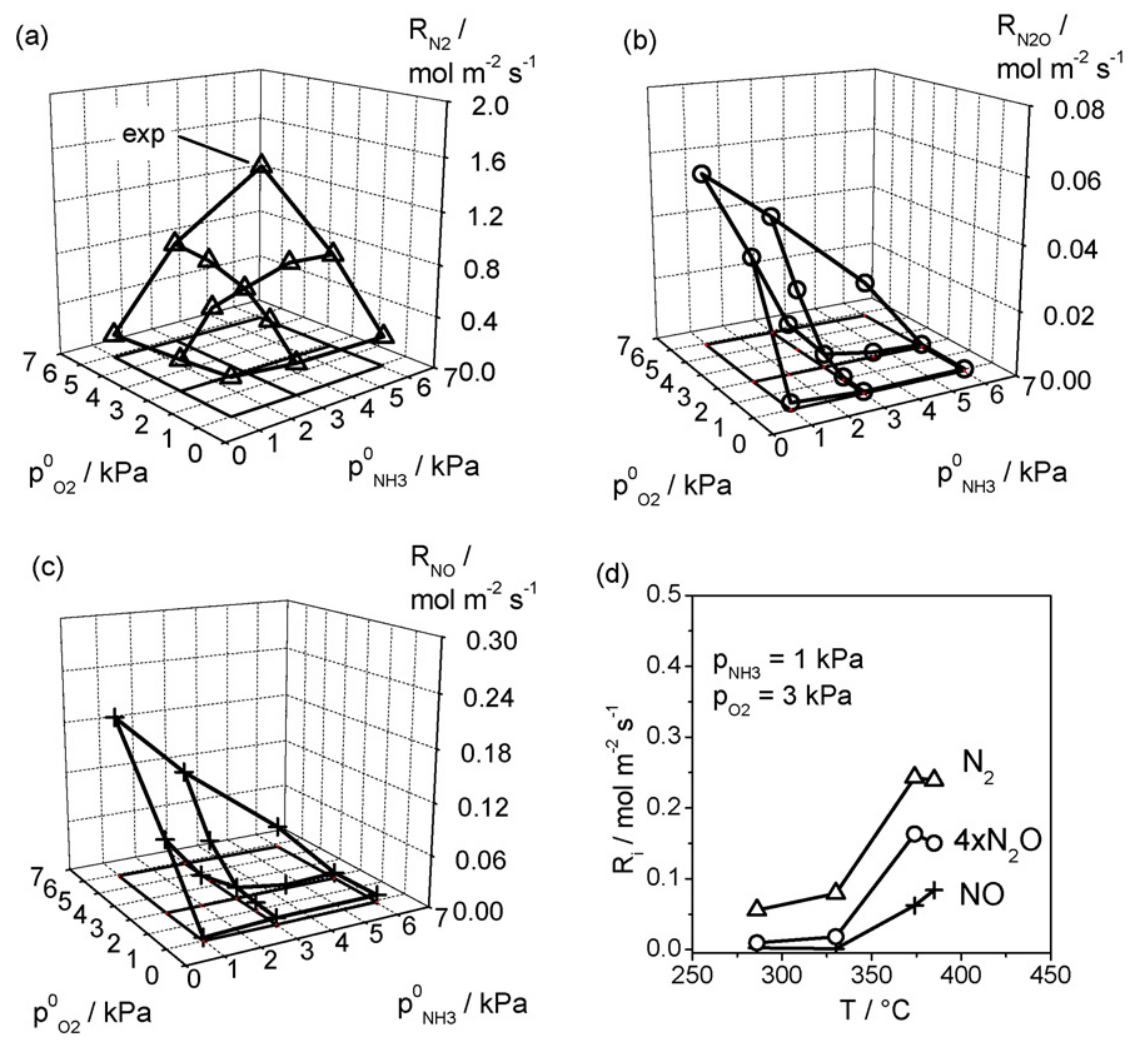

Fig. 3. (a-c) Influence of partial pressure of oxygen and ammonia on rate of product formation in catalytic ammonia oxidation at $385^{\circ} \mathrm{C}(400 \mathrm{ml} / \mathrm{min}, 1-6 \mathrm{kPa} \mathrm{NH} 3$, 1-6 $\mathrm{kPa} \mathrm{O}_{2}$ ). (a) $\mathrm{N}_{2}$ formation; (b) $\mathrm{N}_{2} \mathrm{O}$ formation; (c) $\mathrm{NO}$ formation; (d) influence of temperature on the rates of formation of $\mathrm{N}_{2}, \mathrm{~N}_{2} \mathrm{O}$ and $\mathrm{NO}(400 \mathrm{ml} / \mathrm{min}, 1 \mathrm{kPa}$ $\mathrm{NH}_{3}, 3 \mathrm{kPa} \mathrm{O}$ ).

excess of oxygen. The influence of feed composition on product formation at other temperatures was similar to that shown in Fig. 3a-c, with the difference that NO was not formed in the low-temperature regime. It has to be noted that for all temperatures the rate of ammonia consumption decreased neither in large oxygen excess, nor in large ammonia excess. Since the products of ammonia oxidation are formed from adsorbed oxygen and $\mathrm{NH}_{x}$ species (see Section 4), a competition between oxygen and ammonia for adsorption sites is unlikely.

The observed influence of partial pressures of oxygen and ammonia on rates of formation of $\mathrm{N}_{2}$ and $\mathrm{NO}$ agrees qualitatively with previously reported data for flow experiments at low pressure $[9,19,30]$ and atmospheric pressure $[15,16]$. Compared to the data of Rebrov et al. $[15,16]$, who studied the effect of varying feed composition on selectivity towards $\mathrm{N}_{2} \mathrm{O}$ at almost complete ammonia conversion $\left(X_{\mathrm{NH}_{3}}=80-100 \%\right)$, the changes of $R_{\mathrm{N}_{2} \mathrm{O}}$ with feed composition are much more pronounced in the present data. The differences may be due to the fact that the $\mathrm{NH}_{3}$ to $\mathrm{O}_{2}$ ratio was varied in a wider range in the present study, and that rate data were measured at conversions significantly below $80 \%$.

\subsection{Partial pressure of $\mathrm{NO}$ and $\mathrm{N}_{2} \mathrm{O}$}

The presence of the reaction products $\mathrm{N}_{2} \mathrm{O}$ and $\mathrm{NO}$ in the ammonia-oxygen-feed can change the rate of formation of all
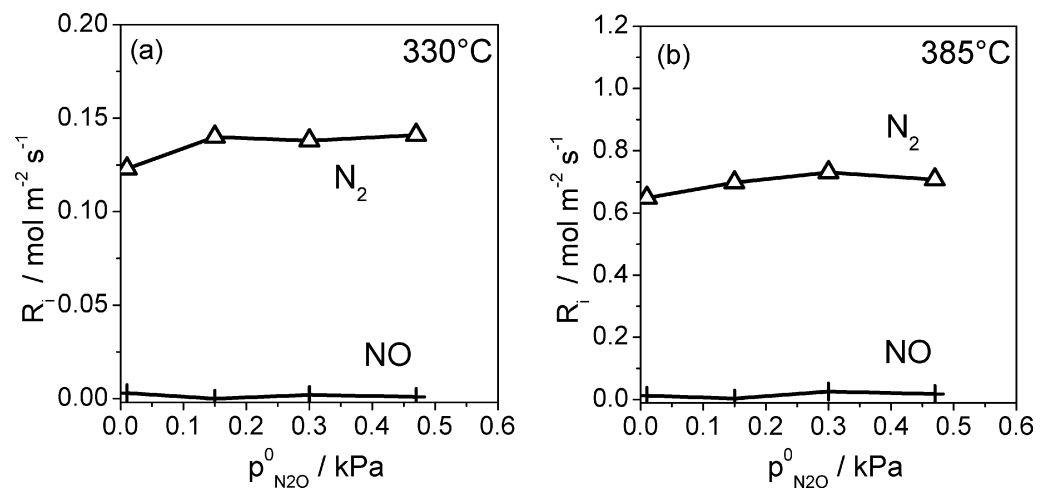

Fig. 4. Influence of partial pressure of $\mathrm{N}_{2} \mathrm{O}$ on rate of product formation in catalytic ammonia oxidation at 330 and $385^{\circ} \mathrm{C}\left(400 \mathrm{ml} / \mathrm{min}, 3 \mathrm{kPa} \mathrm{NH} 3,3 \mathrm{kPa} \mathrm{O}_{2}\right)$. 
products due to secondary reactions with feed molecules or competition for adsorption sites. Representative examples for the measured rates of product formation when adding different amounts of $\mathrm{N}_{2} \mathrm{O}$ and $\mathrm{NO}$ to a feed containing $3 \mathrm{kPa} \mathrm{NH}_{3}$ and $3 \mathrm{kPa} \mathrm{O}_{2}$ are shown in Figs. 4 and 5 for the low-temperature and the high-temperature regime, respectively.

As illustrated by Fig. 4, the influence of adding $\mathrm{N}_{2} \mathrm{O}$ induced negligible changes on the formation of the other products in the whole temperature range. In contrast, adding nitric oxide changed the product formation markedly (Fig. 5). In the lowtemperature regime (Fig. 5a), i.e. in absence of NO formation, the additional $\mathrm{NO}$ drastically decreased the rate of $\mathrm{N}_{2}$ formation, but increased the formation of $\mathrm{N}_{2} \mathrm{O}$. Product distribution in the regime of $\mathrm{NO}$ formation $\left(374\right.$ and $385^{\circ} \mathrm{C}$ ) changed only slightly when $\mathrm{NO}$ was added, responding with a minimal increase in $\mathrm{N}_{2}$ formation as well as a somewhat higher rate of $\mathrm{N}_{2} \mathrm{O}$ formation (Fig. 5b).

The negligible influence of $\mathrm{N}_{2} \mathrm{O}$ on product formation in ammonia oxidation indicates that molecular adsorption of $\mathrm{N}_{2} \mathrm{O}$ is weak, and hence, $\mathrm{N}_{2} \mathrm{O}$ does not block adsorption sites on the catalyst surface. It also indicates that dissociative $\mathrm{N}_{2} \mathrm{O}$ adsorption, observed for $\mathrm{Pt}-\mathrm{SiO}_{2}$ and $\mathrm{Pt}-\mathrm{C}$ near room temperature [34-36], does not occur at a significant rate under conditions of ammonia oxidation, i.e. in the presence of oxygen. Thus, secondary reactions involving $\mathrm{N}_{2} \mathrm{O}$ can be neglected for the experimental conditions of the present study.

In contrast, the rate of ammonia consumption was decreased by nitric oxide at 286 and $330^{\circ} \mathrm{C}$ (Fig. 5a). Such inhibition of ammonia oxidation must be reflected in a kinetic model, and is possibly explained by site blocking on the Pt surface due to strongly adsorbed NO molecules. The idea of strong NO adsorption is consistent with the reported desorption temperature of nitric oxide in vacuum, ca. $70-230^{\circ} \mathrm{C}$ [37-40], and suggests that a term for $\mathrm{NO}$ adsorption should be included into respective kinetic models. With increasing temperature of ammonia oxidation, the rate of $\mathrm{NO}$ desorption increases, and hence the associated site blocking becomes less evident. The experimental data are in agreement with the qualitative observation of Katona et al. [41] that ammonia oxidation, studied in batch experiments over Pt foil at $220^{\circ} \mathrm{C}$, was slowed down by the presence of NO. That the measured rate of $\mathrm{N}_{2} \mathrm{O}$ formation increased at all temperatures when $\mathrm{NO}$ was added to the $\mathrm{NH}_{3}+\mathrm{O}_{2}$ feed (Fig. 5) points towards a participation of $\mathrm{NO}$ in the formation of $\mathrm{N}_{2} \mathrm{O}$.

In the only reported study of ammonia oxidation performed under conditions comparable to the present ones (Rebrov et al. $[15,16], \mathrm{Pt} / \mathrm{Al}_{2} \mathrm{O}_{3}, 260-360^{\circ} \mathrm{C}$ ), the influence of adding reaction products to the feed mixture was not investigated. Moreover, also previous low-pressure kinetic studies of ammonia oxidation $[6,8,9,30]$ were conducted in the binary system $\mathrm{NH}_{3}+\mathrm{O}_{2}$ at low conversion (differential reactor). Hence, information about secondary reactions and the influence of products on the kinetics had not been obtained.

\section{Modeling and simulation results}

The mechanistic basis of the micro-kinetic models is developed in Section 4.1. Thereafter, the models and respective simulation results are presented (Sections 4.2-4.4). Finally, the models are discriminated (Section 4.5) and the kinetics are discussed with respect to the achieved description of experimental data (Section 4.6).

\subsection{Basis of the kinetic models}

Kinetic models were set up in the following way: mechanistic models were assembled from literature data (Section 4.1.1), and simplified to reduce the number of kinetic parameters (Section 4.1.2). For the surface species included in the reaction steps, adsorption sites were assigned based on literature data for an assumed Pt model surface, i.e. a representative flat Pt single crystal. Thereafter, rate equations were derived (see Section 2.3.3).

Improvements of the kinetic model, as compared to the models suggested in literature, were guided by the experimental results presented in Section 3. Since adding $\mathrm{N}_{2} \mathrm{O}$ to the $\mathrm{NH}_{3}-\mathrm{O}_{2}$ feed did not change the product distribution, secondary reactions of $\mathrm{N}_{2} \mathrm{O}$ can be omitted. In contrast, adding $\mathrm{NO}$ to the feed containing ammonia and oxygen should be reflected in the model with an inhibiting term at lower temperatures, and with an increase in the formation of $\mathrm{N}_{2} \mathrm{O}$. Finally, experimentally observed inhibition of product formation in excess of both oxygen and ammonia is negligible. Hence, the following kinetic models were tested:
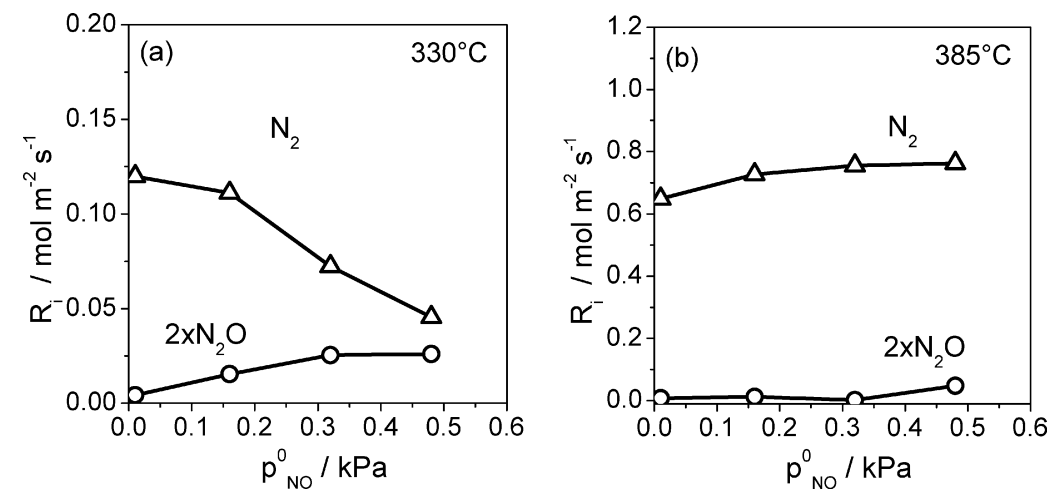

Fig. 5. Influence of partial pressure of $\mathrm{NO}$ on rate of product formation in catalytic ammonia oxidation at 330 and $385^{\circ} \mathrm{C}\left(400 \mathrm{ml} / \mathrm{min}, 3 \mathrm{kPa} \mathrm{NH} 3,3 \mathrm{kPa} \mathrm{O}_{2}\right)$. 
(A) based on the kinetics for $\operatorname{Pt}(533)$ of Scheibe et al. [8,10],

(B) based on the best kinetic model for $\mathrm{Pt} / \mathrm{Al}_{2} \mathrm{O}_{3}$ of Rebrov et al. [16], and

(C) a suggested alternative model.

The results indicate that the assignment of surface species to adsorption sites as well as the terms reflecting $\mathrm{NO}$ adsorption are important factors influencing the model quality. The mechanistic basis of model building is briefly introduced below in order to facilitate the subsequent presentation of model details.

\subsubsection{Suggested reaction mechanism}

The literature summarized below provides the mechanistic framework on an atomistic level, from which the studied kinetic models were build $[10,15]$. The reaction steps that have to be considered are adsorption of feed molecules $\left(\mathrm{NH}_{3}\right.$ and $\left.\mathrm{O}_{2}\right)$, activation of adsorbed ammonia molecules by $\mathrm{H}$-abstraction, the formation and desorption of reaction products $\left(\mathrm{N}_{2}, \mathrm{~N}_{2} \mathrm{O}\right.$, NO and $\mathrm{H}_{2} \mathrm{O}$ ), as well as re-adsorption of products and secondary reactions.

General agreement exists that ammonia adsorbs in on-top position on $\mathrm{Pt}\left(\mathrm{Pt}\left(\begin{array}{lll}1 & 1 & 1\end{array}\right)\right.$ : [42-45]) independent of Pt crystal plane $[46,47]$. Ammonia adsorption is assumed to be a non-activated process $[10,15]$. The catalytically interesting low-coverage state of adsorbed ammonia desorbs around $30-110^{\circ} \mathrm{C}[46,47]$, i.e. ca. $200 \mathrm{~K}$ below the presently studied temperatures, with an activation energy of desorption of ca. 75-96 kJ/mol.

Adsorption of $\mathrm{O}_{2}$ on platinum is usually assumed to be dissociative. The reaction has been described as non-activated process with either constant initial sticking probability [16,48-50], or an initial sticking coefficient that decreased with increasing temperature, resulting in slightly negative apparent activation energies (Pt(1 11 1): $E_{\mathrm{A}} \hat{=}-2.6 \mathrm{~kJ} / \mathrm{mol}[51] ; \mathrm{Pt}(443): E_{\mathrm{A}}=-7.5 \mathrm{~kJ} / \mathrm{mol}$ [10]). Maximum coverage of adsorbed oxygen atoms and initial sticking coefficients vary with Pt crystal plane [51-53]. Moreover, dissociative oxygen adsorption on $\mathrm{Pt}$ is a reversible reaction. Depending on $\mathrm{Pt}$ surface and oxygen coverage, activation energies for the recombination-desorption varied significantly between 105 and $215 \mathrm{~kJ} / \mathrm{mol}$ ([15] and references therein).

Reactions proposed for the activation of ammonia molecules on Pt surfaces are decomposition [46,54,55], reaction with adsorbed oxygen atoms [56,57], and reaction with adsorbed hydroxyl groups, where $\mathrm{OH}_{\text {ads }}$ is generated by $\mathrm{NH}_{x}+\mathrm{O}$ interactions [19,57-60]. DFT studies [61] confirmed that stepwise abstraction of hydrogen atoms from $\mathrm{NH}_{3}$ by reaction with $\mathrm{O}$ and $\mathrm{OH}$ are fast compared to decomposition of $\mathrm{NH}_{x}$, and that the reaction path of ammonia decomposition can therefore be neglected.

The recombination-desorption of adsorbed nitrogen atoms is commonly assumed to be the main route of $\mathrm{N}_{2}$ formation $[10,15,16,31,62,63]$. Alternative reactions between $\mathrm{NH}_{x}$ species forming $\mathrm{N}_{2}$ and $\mathrm{H}_{2}$ do not proceed in the presence of oxygen [32].

Formation of NO is often described as recombination of adsorbed $\mathrm{O}$ and $\mathrm{N}$ atoms $[10,15]$. Depending on the studied $\mathrm{Pt}$ surface plane and on temperature, nitric oxide desorbs [37,39], decomposes $[37,39,56]$, or reacts to $\mathrm{N}_{2} \mathrm{O}[15,64]$. The competition between these reactions determines the selectivity towards $\mathrm{NO}$ and $\mathrm{N}_{2} \mathrm{O}$. The formation of $\mathrm{N}_{2} \mathrm{O}$ via $\mathrm{N}+\mathrm{NO}$ reaction was shown to be energetically favored over formation and subsequent decomposition of an (NO) $)_{2}$ dimer [64-66]. Some authors proposed product formation via $\mathrm{HNO}_{\text {ads }}$ intermediate for $\mathrm{N}_{2} \mathrm{O}$ [67], $\mathrm{NO}$ [68] and $\mathrm{N}_{2}$ [67,69], but so far no experimental proof has been obtained for the presence of $\mathrm{HNO}$ on the catalyst surface during catalytic ammonia oxidation [10].

The $\mathrm{OH}$ formed in ammonia activation contributes to the formation of water, the only hydrogen-containing product of ammonia oxidation detected in the present study. Water can be formed on the $\mathrm{Pt}$ surface via reaction $\mathrm{OH}+\mathrm{H}[48,70]$, via $\mathrm{OH}+\mathrm{OH}[48,70]$, and via $\mathrm{NH}_{x}+\mathrm{OH}[18,59]$. The subsequent desorption is fast, leading to a negligible surface coverage of water under reaction conditions $[10,16,70]$.

Possible secondary reactions of the ammonia-oxidation products $\mathrm{NO}$ and $\mathrm{N}_{2} \mathrm{O}$ can be accounted for by dissociative adsorption of $\mathrm{N}_{2} \mathrm{O}$ on the $\mathrm{Pt}$ surface, and by molecular $\mathrm{NO}$ adsorption followed by the already described reactions of $\mathrm{NO}_{\text {ads }}$. Interactions between $\mathrm{N}_{2}$ and $\mathrm{Pt}$ are negligible between 20 and $800^{\circ} \mathrm{C}$ [33]. The presented mechanistic framework, in combination with the model simplification discussed below (Section 4.1.2), formed the basis of the studied kinetic models (see Sections 4.2-4.4).

\subsubsection{Implementation of the kinetic models and required simplifications}

Several features are shared among all tested model: The adsorption of ammonia is modeled by non-activated molecular adsorption [10,15], and is assumed to be reversible. Moreover, non-activated reversible dissociative $\mathrm{O}_{2}$ adsorption $[16,48-50,71]$ is supposed $\left(E_{\mathrm{A}}^{\mathrm{O}_{2}}\right.$ ads $\left.\equiv 0\right)$. Furthermore, the simplifying assumption is made that the kinetics of oxygen desorption are coverage independent. As implemented by Rebrov et al. [16] and Scheibe et al. [10], the stepwise ammonia activation by adsorbed atomic oxygen is lumped into one stoichiometric reaction, assuming the first step $\left(\mathrm{NH}_{3}+\mathrm{O}\right)$ to be rate determining and a first-order reaction with respect to $\mathrm{NH}_{3}$ and $\mathrm{O}$. Since both mentioned kinetic studies $[10,16]$ found negligibly small surface coverage of $\mathrm{H}$ and $\mathrm{OH}$, and water desorption is known to be fast, water formation was also included in this lumped reaction step. Production of $\mathrm{N}_{2}$ and NO is described by the respective recombination reactions $(\mathrm{N}+\mathrm{N}, \mathrm{N}+\mathrm{O})$. While $\mathrm{N}_{2}$ desorption is fast, adsorbed nitric oxide can either desorb or undergo further reaction, i.e. dissociation or $\mathrm{N}_{2} \mathrm{O}$ formation. Formation of nitrous oxide is accounted for by a surface reaction between $\mathrm{N}$ and NO.

The kinetic models differ in the site assignment for adsorbed species. In model A [10], site uniformity was assumed. Model B [16] considered two energetically different adsorption sites ( $a$ and $b$ ); the site assignment of adsorbed species was inferred from the assumption that the surfaces resembles a flat single

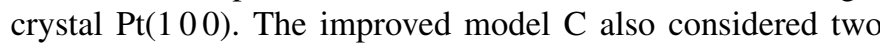
energetically different adsorption sites ( $a$ and $b$ ), but the site assignment of adsorbate species was based on the known preferences of adsorbates on a $\operatorname{Pt}\left(\begin{array}{lll}1 & 1 & 1\end{array}\right)$ surface. Further differences between the models exist in the fact that re-adsorption of $\mathrm{NO}$ 


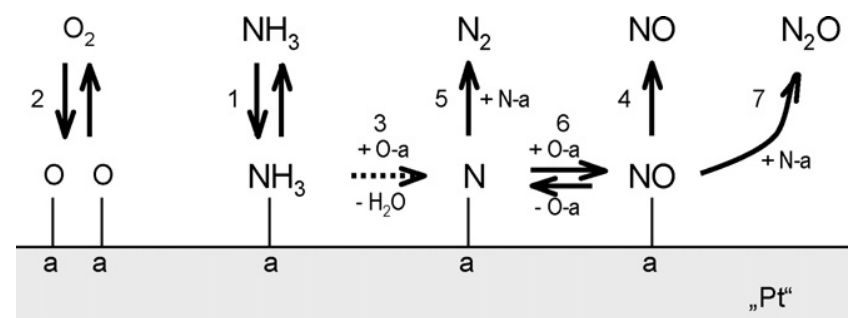

Fig. 6. Model A: mechanistic scheme of the included reaction steps of ammonia oxidation, indicating elementary reactions (solid line) and a lumped reaction (dashed line).

is only considered in model $\mathrm{C}$, and that only models $\mathrm{A}$ and $\mathrm{B}$ contain the NO decomposition step.

An assumption made in the computation is that the surface is a uniform rigid substrate. Moreover, the concentration of active sites on the surface was supposed to be independent of reaction conditions and time, and equivalent to the number of Pt surface atoms. Furthermore, all adsorption sites of one type ( $a$ and $b$ ) are energetically equivalent, and activation energies are coverageindependent. Finally, axial and radial gradients of temperature and concentration were assumed to be negligible (i.e., isothermal differential reactor in kinetic regime).

\subsection{Model A}

The tested model "A" was based on the kinetics of ammonia oxidation as derived by Scheibe et al. $[8,10]$ at pressures up to $10^{-2} \mathrm{~Pa}$ for $\mathrm{Pt}(533)$. A mechanistic scheme of the model and respective rate equations are given in Fig. 6 and Table 1, respectively. Energetic uniformity of adsorption sites "a" was assumed. Since formation of $\mathrm{N}_{2} \mathrm{O}$ was observed in the present study, but not at the lower pressure applied by Scheibe et al., an expression for $\mathrm{N}_{2} \mathrm{O}$ formation was added to their model.

Figs. $7 \mathrm{a}$ and $\mathrm{b}$ shows how the model describes the rate of formation of the main product nitrogen in both the lower and higher reaction-temperature regimes, respectively, as a function of oxygen and ammonia partial pressure. It is evident from the plots that especially at low temperatures, where $\mathrm{N}_{2}$ is formed almost exclusively, simulated and experimental trends deviate significantly: while the model predicts a decrease in the rate of $\mathrm{N}_{2}$ formation in large excess of oxygen as well as in large excess
Table 1

Model A: reactions, rate equations, mass balance of surface species, adsorption sites

\begin{tabular}{ll}
\hline Reaction & Rate equation \\
\hline $\mathrm{NH}_{3}+\mathrm{a} \rightleftarrows \mathrm{NH}_{3}-\mathrm{a}$ & $r_{1 \mathrm{~h}}=k_{1 \mathrm{~h}} p_{\mathrm{NH}_{3}} \Theta_{\mathrm{a}} ; r_{1 \mathrm{r}}=k_{1 \mathrm{r}} \Theta_{\mathrm{NH}_{3}-\mathrm{a}}$ \\
$\mathrm{O}_{2}+2 \mathrm{a} \rightleftarrows 2 \mathrm{O}-\mathrm{a}$ & $r_{2 \mathrm{~h}}=k_{2 \mathrm{~h}} p_{\mathrm{O}_{2}} \Theta_{\mathrm{a}}^{2} ; r_{2 \mathrm{r}}=k_{2 \mathrm{r}} \Theta_{\mathrm{O}-\mathrm{a}}^{2}$ \\
$\mathrm{NH}_{3}-\mathrm{a}+(3 / 2) \mathrm{O}-\mathrm{a} \rightarrow \mathrm{N}-$ & $r_{3 \mathrm{~h}}=k_{3 \mathrm{~h}} \Theta_{\mathrm{NH}_{3}-\mathrm{a}} \Theta_{\mathrm{O}-\mathrm{a}}$ \\
$\quad \mathrm{a}+(3 / 2) \mathrm{H}_{2} \mathrm{O}+(3 / 2) \mathrm{a}$ & \\
$\mathrm{NO}-\mathrm{a} \rightarrow \mathrm{NO}+\mathrm{a}$ & $\mathrm{r}_{4 \mathrm{~h}}=\mathrm{k}_{4 \mathrm{~h}} \Theta_{\mathrm{NO}-\mathrm{a}}$ \\
$2 \mathrm{~N}-\mathrm{a} \rightarrow \mathrm{N}_{2}+2 \mathrm{a}$ & $\mathrm{r}_{5 \mathrm{~h}}=\mathrm{k}_{5 \mathrm{~h}} \Theta_{\mathrm{N}-\mathrm{a}}^{2}$ \\
$\mathrm{~N}-\mathrm{a}+\mathrm{O}-\mathrm{a} \rightleftarrows \mathrm{NO}-\mathrm{a}+\mathrm{a}$ & $\mathrm{r}_{6 \mathrm{~h}}=\mathrm{k}_{6 \mathrm{~h}} \Theta_{\mathrm{N}-\mathrm{a}} \Theta_{\mathrm{O}-\mathrm{a}} ; \mathrm{r}_{6 \mathrm{r}}=\mathrm{k}_{6 \mathrm{r}} \Theta_{\mathrm{NO}-\mathrm{a}} \Theta_{\mathrm{a}}$ \\
$\mathrm{NO}-\mathrm{a}+\mathrm{N}-\mathrm{a} \rightarrow \mathrm{N}_{2} \mathrm{O}+2 \mathrm{a}^{\mathrm{a}}$ & $\mathrm{r}_{7 \mathrm{~h}}=\mathrm{k}_{7 \mathrm{~h}} \Theta_{\mathrm{NO}-\mathrm{a}} \Theta_{\mathrm{N}-\mathrm{a}}$ \\
\hline
\end{tabular}

Adsorption site-(a) $\mathrm{O}, \mathrm{N}, \mathrm{NH}_{3}, \mathrm{NO}: \Theta_{\mathrm{a}}=1-\Theta_{\mathrm{O}-\mathrm{a}}-\Theta_{\mathrm{N}-\mathrm{a}}-\Theta_{\mathrm{NH}_{3}-\mathrm{a}}-$ $\Theta_{\mathrm{NO}-\mathrm{a}}$.

${ }^{\text {a }}$ Reaction for $\mathrm{N}_{2} \mathrm{O}$-formation added to the published model.

of ammonia, such decrease was not observed experimentally. This inhibition effect by $\mathrm{O}_{2}$ as well as $\mathrm{NH}_{3}$ is inherent to the model since both feed species, oxygen and ammonia, occupy the same adsorption site: if one species dominantly covers the surface, the other species is blocked. Since both $\mathrm{NH}_{3}$,ads and $\mathrm{O}_{\text {ads }}$ are required to form products, the reaction then ceases. Due to the inability of the model to describe such basic trends as the influence of feed composition on the rate of the formation of the main product, the model was discarded.

\subsection{Model B}

Model $\mathrm{B}$ is based on the best kinetic model derived by Rebrov et al. [16] for ammonia oxidation over $\mathrm{Pt} / \mathrm{Al}_{2} \mathrm{O}_{3}$ near atmospheric pressure. The assignment of adsorption sites [16] followed literature data on $\operatorname{Pt}\left(\begin{array}{ll}0 & 0\end{array}\right)$, assuming bridge and hollow sites (a: $\mathrm{N}$ and $\mathrm{O}$ ) to be energetically equivalent, and ammonia and NO to reside in on-top positions (b: $\mathrm{NH}_{3}$ and $\mathrm{NO}$ ). A mechanistic scheme of model $\mathrm{B}$ and the rate equations are listed in Fig. 8 and Table 2, respectively. Following the original model [16], NO dissociation was included into the model, but not readsorption of NO. $\mathrm{N}_{2} \mathrm{O}$ formation proceeds via reaction between adsorbed $\mathrm{NO}$ and $\mathrm{N}$.

Representative results of the best-fitting solution of the model are given in Fig. 9 in comparison to experimental data, showing the influence of feed composition $\left(p_{\mathrm{NH}_{3}}, p_{\mathrm{O}_{2}}\right)$ on the formation (a)

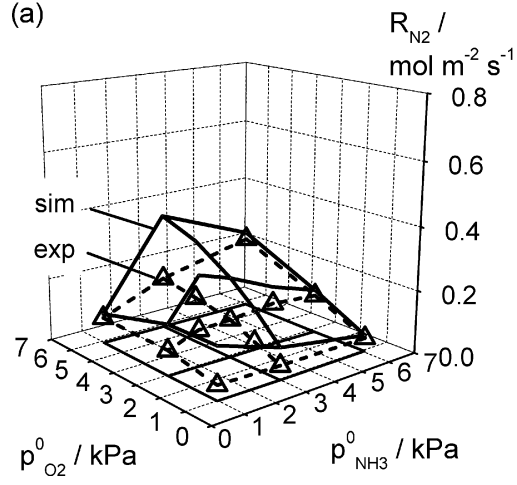

(b)

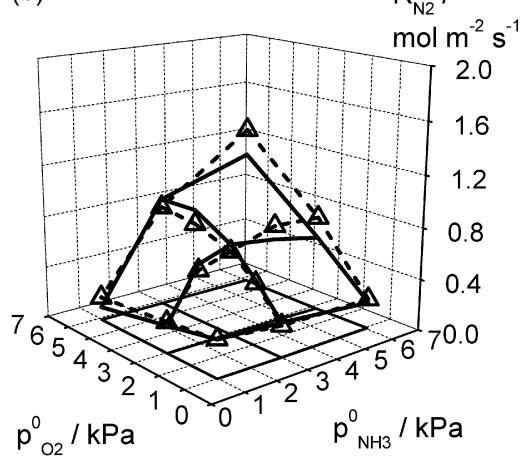

Fig. 7. Model A: influence of partial pressure of oxygen and ammonia, experiment vs. simulation. (a) Rate of $\mathrm{N}_{2}$ formation at $330^{\circ} \mathrm{C}$ and (b) rate of $\mathrm{N}_{2}$ formation at $385^{\circ} \mathrm{C}$. 


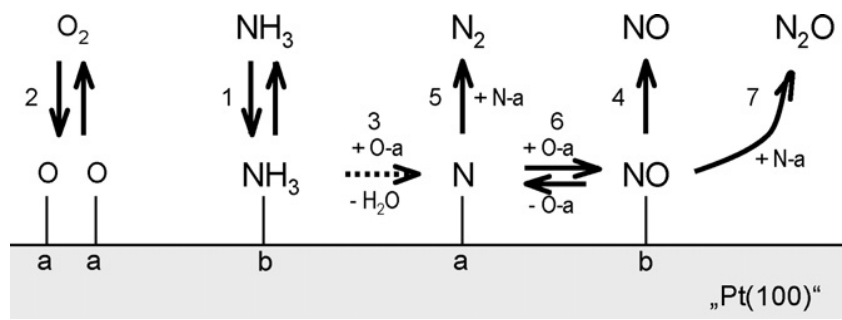

Fig. 8. Model B: mechanistic scheme of the included reaction steps of ammonia oxidation, indicating elementary reactions (solid line) and a lumped reaction (dashed line).

of $\mathrm{N}_{2}$ (Fig. 9a), $\mathrm{NO}$ (Fig. 9b) and $\mathrm{N}_{2} \mathrm{O}$ (Fig. 9c), as well as the influence of temperature on the formation of all three products (Fig. 9d).

The influence of feed composition on rates of product formation is described well for both main products, $\mathrm{N}_{2}$ and NO. The achieved description for $\mathrm{N}_{2} \mathrm{O}$ is also good, but shows a slight deviation in large oxygen excess. In contrast, the effect of increasing temperature is reproduced well by the model for the formation of $\mathrm{NO}$ and $\mathrm{N}_{2} \mathrm{O}$, but deviates somehow for nitrogen. Overall, a reasonable description of the experimental data is achieved. Nevertheless, due to the lack of a term for readsorption of NO, the model cannot describe two key observations of the kinetic measurements: inhibition of ammonia oxidation at low temperatures by adding $\mathrm{NO}$ to the feed containing ammonia and oxygen, and enhanced $\mathrm{N}_{2} \mathrm{O}$ formation in the presence of $\mathrm{NO}$.
Table 2

Model B: Reactions, rate equations, mass balance of surface species, adsorption sites

\begin{tabular}{ll}
\hline Reaction & Rate equation \\
\hline $\mathrm{NH}_{3}+\mathrm{b} \rightleftarrows \mathrm{NH}_{3}-\mathrm{b}$ & $r_{1 \mathrm{~h}}=k_{1 \mathrm{~h}} p_{\mathrm{NH}_{3}} \Theta_{\mathrm{b}} ; r_{1 \mathrm{r}}=k_{1 \mathrm{r}} \Theta_{\mathrm{NH}_{3}-\mathrm{b}}$ \\
$\mathrm{O}_{2}+2 \mathrm{a} \rightleftarrows 2 \mathrm{O}-\mathrm{a}$ & $r_{2 \mathrm{~h}}=k_{2 \mathrm{~h}} p_{\mathrm{O}_{2}} \Theta_{\mathrm{a}}^{2} ; r_{2 \mathrm{r}}=k_{2 \mathrm{r}} \Theta_{\mathrm{O}-\mathrm{a}}^{2}$ \\
$\mathrm{NH}_{3}-\mathrm{b}+(3 / 2) \mathrm{O}-\mathrm{a} \rightarrow \mathrm{N}-$ & $r_{3 \mathrm{~h}}=k_{3 \mathrm{~h}} \Theta_{\mathrm{NH}_{3}-\mathrm{b}} \Theta_{\mathrm{O}-\mathrm{a}}$ \\
$\mathrm{a}+(3 / 2) \mathrm{H}_{2} \mathrm{O}+(1 / 2) \mathrm{a}+\mathrm{b}$ & \\
$\mathrm{NO}-\mathrm{b} \rightarrow \mathrm{NO}+\mathrm{b}$ & $r_{4 \mathrm{~h}}=k_{4 \mathrm{~h}} \Theta_{\mathrm{NO}-\mathrm{b}}$ \\
$2 \mathrm{~N}-\mathrm{a} \rightarrow \mathrm{N}_{2}+2 \mathrm{a}$ & $r_{5 \mathrm{~h}}=k_{5 \mathrm{~h}} \Theta_{\mathrm{N}-\mathrm{a}}^{2}$ \\
$\mathrm{~N}-\mathrm{a}+\mathrm{O}-\mathrm{a}+\mathrm{b} \rightleftarrows \mathrm{NO}-\mathrm{b}+2 \mathrm{a}$ & $r_{6 \mathrm{~h}}=k_{6 \mathrm{~h}} \Theta_{\mathrm{N}-\mathrm{a}} \Theta_{\mathrm{O}-\mathrm{a}}^{\mathrm{a}} ; r_{6 \mathrm{r}}=k_{6 \mathrm{r}} \Theta_{\mathrm{NO}-\mathrm{b}} \Theta_{\mathrm{A}}^{2}$ \\
$\mathrm{NO}-\mathrm{b}+\mathrm{N}-\mathrm{a} \rightarrow \mathrm{N}_{2} \mathrm{O}+\mathrm{a}+\mathrm{b}$ & $r_{7 \mathrm{~h}}=k_{7 \mathrm{~h}} \Theta_{\mathrm{NO}-\mathrm{b}} \Theta_{\mathrm{N}-\mathrm{a}}$ \\
\hline
\end{tabular}

Adsorption sites-(a) $\mathrm{O}, \mathrm{N}: \Theta_{\mathrm{a}}=1-\Theta_{\mathrm{O}-\mathrm{a}}-\Theta_{\mathrm{N}-\mathrm{a}}$; (b) $\mathrm{NH}_{3}, \mathrm{NO}: \Theta_{\mathrm{b}}=1-$ $\Theta_{\mathrm{NH}_{3}-\mathrm{b}}-\Theta_{\mathrm{NO}-\mathrm{b}}$

${ }^{\text {a }}$ Rate equation is identical to that of Rebrov et al. [16], $\Theta_{\mathrm{b}}$ not included there.

\subsection{Model C}

The model "C" was developed in a similar fashion as model $\mathrm{B}$, but assuming $\mathrm{Pt}\left(\begin{array}{lll}1 & 1 & 1\end{array}\right)$ as a model surface for polycrystalline $\mathrm{Pt}$ (model B: $\mathrm{Pt}(100)$ [16]). The assumption is reasonable, since macroscopic pieces of a fcc metal surface generally expose predominantly the thermodynamically most stable (1 111$)$-type surface planes. This consideration has two important consequences: the site assignment for NO differs from model B, and adsorbed NO does not dissociate on $\operatorname{Pt}\left(\begin{array}{lll}1 & 1 & 1\end{array}\right)$. In addition, based on the experimental evidence (Fig. 5) adsorption of nitric oxide was incorporated into the model. A mechanistic scheme

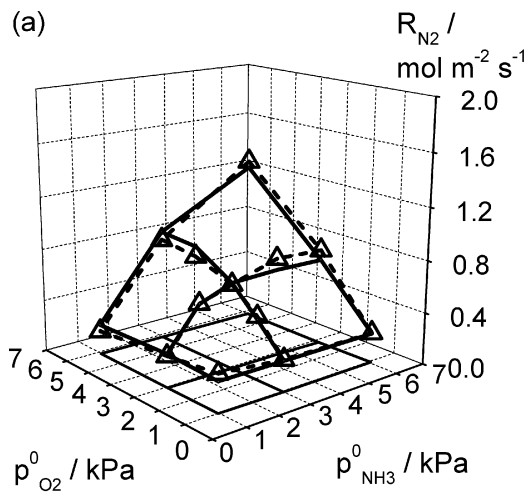

(c)

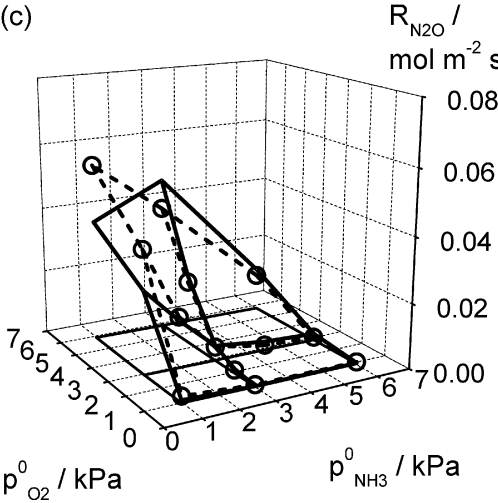

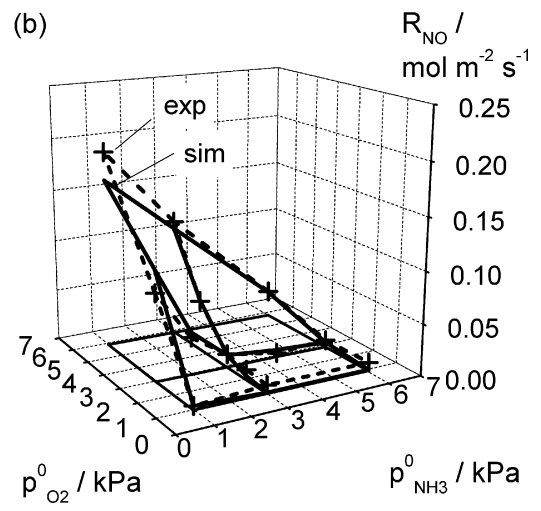

(d)

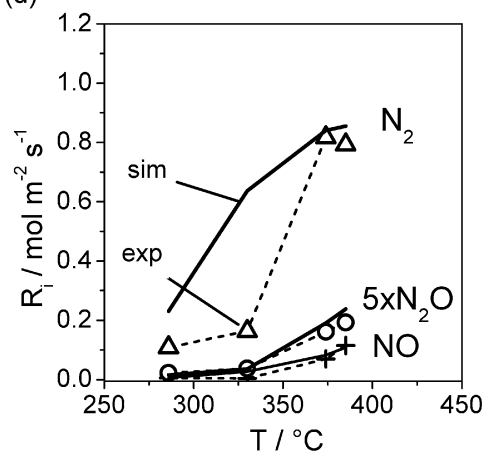

Fig. 9. (a-c) Model B: influence of partial pressure of oxygen and ammonia, experiment vs. simulation. (a) Rate of $\mathrm{N}_{2}$ formation at $385^{\circ} \mathrm{C}$; (b) rate of $\mathrm{NO}$ formation at $385^{\circ} \mathrm{C}$; (c) rate of $\mathrm{N}_{2} \mathrm{O}$ formation at $385^{\circ} \mathrm{C}$; (d) influence of temperature on the rates of formation of $\mathrm{N}_{2}, \mathrm{~N}_{2} \mathrm{O}$ and $\mathrm{NO}$, experiment vs. simulation $\left(p_{\mathrm{NH}}=3 \mathrm{kPa}\right.$, $\left.p_{\mathrm{O}_{2}}=6 \mathrm{kPa}\right)$. 
Table 3

Model C: Reactions, rate equations, kinetic parameters, mass balance of surface species, adsorption sites; kinetic constants from literature

\begin{tabular}{|c|c|c|c|c|c|}
\hline Reaction & Rate equation & $k_{i, T}=385^{\circ} \mathrm{C}\left(\mathrm{mol} \mathrm{m}^{-2} \mathrm{~s}^{-1}\right)$ & $E_{\mathrm{A}, i}($ fit $)(\mathrm{kJ} / \mathrm{mol})$ & $E_{\mathrm{A}, i}$ of Ref. [10] $(\mathrm{kJ} / \mathrm{mol})$ & $E_{\mathrm{A}, i}$ of Ref. [16] $(\mathrm{kJ} / \mathrm{mol})$ \\
\hline $\mathrm{NH}_{3}+\mathrm{b} \rightleftarrows \mathrm{NH}_{3}-\mathrm{b}$ & $\begin{array}{l}r_{1 \mathrm{~h}}=k_{1 \mathrm{~h}} p_{\mathrm{NH}_{3}} \Theta_{\mathrm{b}} \\
r_{1 \mathrm{r}}=k_{1 \mathrm{r}} \Theta_{\mathrm{NH}_{3}-\mathrm{b}}\end{array}$ & $\begin{array}{l}6.38 \mathrm{E}-01^{\mathrm{a}} \\
2.17 \mathrm{E}+00\end{array}$ & $\begin{array}{c}0^{\mathrm{b}} \\
60.9\end{array}$ & $\begin{array}{l}0 \\
75\end{array}$ & $\begin{array}{l}0 \\
96\end{array}$ \\
\hline $\mathrm{O}_{2}+2 \mathrm{a} \rightleftarrows 2 \mathrm{O}-\mathrm{a}$ & $\begin{array}{l}r_{2 \mathrm{~h}}=k_{2 \mathrm{~h}} p_{\mathrm{O}_{2}} \Theta_{\mathrm{a}}^{2} \\
r_{2 \mathrm{r}}=k_{2 \mathrm{r}} \Theta_{\mathrm{O}-\mathrm{a}}^{2}\end{array}$ & $\begin{array}{l}2.94 \mathrm{E}-01^{\mathrm{a}} \\
1.09 \mathrm{E}-10\end{array}$ & $\begin{array}{c}0^{\mathrm{b}} \\
181.0\end{array}$ & $\begin{array}{l}-12 \\
188\end{array}$ & $\begin{array}{l}0 \\
213.2-60 \Theta_{\mathrm{O}}\end{array}$ \\
\hline $\begin{array}{l}\mathrm{NH}_{3}-\mathrm{b}+(3 / 2) \mathrm{O}-\mathrm{a} \rightarrow \mathrm{N}- \\
\mathrm{a}+(3 / 2) \mathrm{H}_{2} \mathrm{O}+(1 / 2) \mathrm{a}+\mathrm{b}\end{array}$ & $r_{3 \mathrm{~h}}=k_{3 \mathrm{~h}} \Theta_{\mathrm{NH}_{3}-\mathrm{b}} \Theta_{\mathrm{O}-\mathrm{a}}$ & $5.91 \mathrm{E}+02$ & 99.5 & (75) & (131) \\
\hline $\mathrm{NO}-\mathrm{a} \rightleftarrows \mathrm{NO}+\mathrm{a}$ & $\begin{array}{l}r_{4 \mathrm{~h}}=k_{4 \mathrm{~h}} \Theta_{\mathrm{NO}-\mathrm{a}} \\
r_{4 \mathrm{r}}=k_{4 \mathrm{r}} \mathrm{p}_{\mathrm{NO}} \Theta_{\mathrm{a}}\end{array}$ & $\begin{array}{l}1.24 \mathrm{E}+00 \\
2.63 \mathrm{E}-01^{\mathrm{a}, \mathrm{c}}\end{array}$ & $\begin{array}{r}154.8 \\
63.5^{\mathrm{c}}\end{array}$ & 155 & 140 \\
\hline $2 \mathrm{~N}-\mathrm{a} \rightarrow \mathrm{N}_{2}+2 \mathrm{a}$ & $r_{5 \mathrm{~h}}=k_{5 \mathrm{~h}} \Theta_{\mathrm{N}-\mathrm{a}}^{2}$ & $6.42 \mathrm{E}+01$ & 139.0 & 85 & 99 \\
\hline $\mathrm{N}-\mathrm{a}+\mathrm{O}-\mathrm{a} \rightarrow \mathrm{NO}-\mathrm{a}+\mathrm{a}$ & $r_{6 \mathrm{~h}}=k_{6 \mathrm{~h}} \Theta_{\mathrm{N}-\mathrm{a}} \Theta_{\mathrm{O}-\mathrm{a}}$ & $9.34 \mathrm{E}+00$ & 135.4 & 88 & 121 \\
\hline $\mathrm{NO}-\mathrm{a}+\mathrm{N}-\mathrm{a} \rightarrow \mathrm{N}_{2} \mathrm{O}+2 \mathrm{a}$ & $r_{7 \mathrm{~h}}=k_{7 \mathrm{~h}} \Theta_{\mathrm{NO}-\mathrm{a}} \Theta_{\mathrm{N}-\mathrm{a}}$ & $5.20 \mathrm{E}+00$ & 155.2 & & 93 \\
\hline
\end{tabular}

Adsorption sites-(a) $\mathrm{O}, \mathrm{N}, \mathrm{NO}: \Theta_{\mathrm{a}}=1-\Theta_{\mathrm{O}-\mathrm{a}}-\Theta_{\mathrm{N}-\mathrm{a}}-\Theta_{\mathrm{NO}-\mathrm{a}}$; (b) $\mathrm{NH}_{3}: \Theta_{\mathrm{b}}=1-\Theta_{\mathrm{NH}_{3}-\mathrm{b}}$.

a $k_{i}$ in $\mathrm{mol} \mathrm{m}^{-2} \mathrm{~s}^{-1} \mathrm{kPa}^{-1}$.

${ }^{\mathrm{b}} E_{\mathrm{A}, i} \equiv 0$.

${ }^{\mathrm{c}}$ Obtained in separate fitting procedure with $r_{\mathrm{N}_{2}}=f\left(p_{\mathrm{NO}}\right)$ data, all other $k_{i}, E_{\mathrm{A}, i}$ fixed.

of model $\mathrm{C}$ as well as the respective rate equations are presented in Fig. 10 and Table 3, respectively.

The energetic preferences of adsorbate species on a $\operatorname{Pt}\left(\begin{array}{lll}1 & 1 & 1\end{array}\right)$ surface are known from DFT calculations of Offermans et al. [61]. If each adsorbate reaches the most stable adsorption configuration, two types of adsorption sites are populated on a $\operatorname{Pt}\left(\begin{array}{lll}1 & 1 & 1\end{array}\right)$ surface: hollow sites (by adsorbed $\mathrm{O}, \mathrm{N}$ and $\mathrm{NO}$ ) and on-top sites $\left(\mathrm{NH}_{3, \text { ads }}\right)$. Accordingly, two different adsorption sites were introduced in the model, sites "a" $(\mathrm{O}, \mathrm{N}$ and $\mathrm{NO})$ and sites " $\mathrm{b}$ " $\left(\mathrm{NH}_{3}\right)$. Assigning the same adsorption site for oxygen and nitric oxide results in site competition between $\mathrm{O}$ and $\mathrm{NO}$, which is also supported by spectroscopic evidence [72,73].

Representative results of the best-fitting solution of model $\mathrm{C}$ are presented in Fig. 11 in comparison to experimental data, illustrating the influence of feed composition $\left(p_{\mathrm{NH}_{3}}, p_{\mathrm{O}_{2}}\right)$ on the formation of $\mathrm{N}_{2}$ (Fig. 11a), $\mathrm{NO}$ (Fig. 11b) and $\mathrm{N}_{2} \mathrm{O}$ (Fig. 11c), and the influence of temperature on the formation of all three products (Fig. 11d).

The influence of feed composition on rates of product formation is described well for all products, although the model predicts slightly too low rates of $\mathrm{N}_{2} \mathrm{O}$ formation in large oxygen excess. Moreover, the influence of raising the temperature is reproduced well by the model for the formation of NO and $\mathrm{N}_{2} \mathrm{O}$, but deviates slightly for nitrogen. Nevertheless, deviations are smaller than observed for model B. Overall fitting quality is reasonable, i.e. all general trends upon varying temperature and

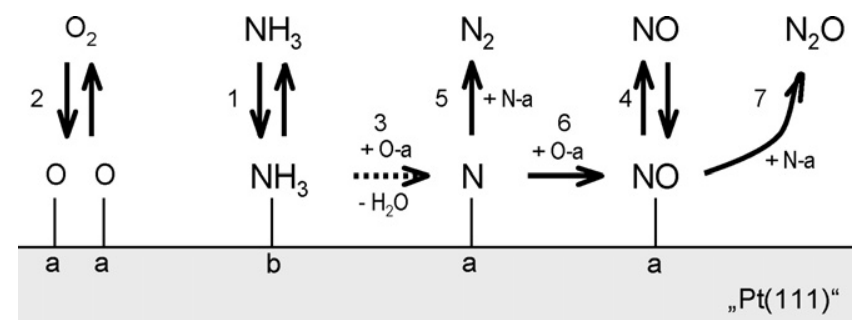

Fig. 10. Model C: mechanistic scheme of the included reaction steps of ammonia oxidation, indicating elementary reactions (solid line) and a lumped reaction (dashed line). feed composition are described. In contrast to models A and B, model $\mathrm{C}$ accounts also for the effect of adding $\mathrm{NO}$ to a feed containing ammonia and oxygen, i.e. increased $\mathrm{N}_{2} \mathrm{O}$ formation, and inhibition of ammonia oxidation at low temperature.

\subsection{Model discrimination}

Pronounced difference between the models existed in the description of the relation between partial pressures of ammonia and oxygen, and rates of $\mathrm{N}_{2}$ formation. While models $\mathrm{B}$ and $\mathrm{C}$ describe the important trends, i.e. increase of the rate of $\mathrm{N}_{2}$ formation with an increase of partial pressures of $\mathrm{NH}_{3}$ and $\mathrm{O}_{2}$ and reaching a constant high level in the excess of one species, model A predicted inhibition in such a case. The inhibition computed by model $\mathrm{A}$ is in contradiction to the experimental data (see Fig. 7), hence model A was discarded.

The discrimination between models $\mathrm{B}$ and $\mathrm{C}$ was based on a comparison of lack-of-fit in the description of formation of the product species $\mathrm{N}_{2}, \mathrm{~N}_{2} \mathrm{O}$ and $\mathrm{NO}$ as presented in Table 4 . As evidenced by the lower values for the deviation between experimental and computed data (lower $\mathrm{SS}_{\mathrm{L}}$ values), a better description was obtained with model $\mathrm{C}$ for all products: the simulation with model $\mathrm{C}$ was better by a factor of 1.8-2.8 (see $F$-value in Table 4$)$. An $F$-test (confidence level $(1-\alpha)=99 \%$ ) indicated that the differences between models $\mathrm{B}$ and $\mathrm{C}$ are not significant in the description of $\mathrm{N}_{2}$ production (" $F$-test passed", Table 4). In contrast, model $\mathrm{C}$ described the formation of $\mathrm{NO}$ and $\mathrm{N}_{2} \mathrm{O}$ significantly better than model B (" $F$-test failed", Table 4 ). Hence, of all tested models A-C, the latter achieved the best agreement between experimental and simulated rates of product formation.

\subsection{Discussion}

A comparison between the tested kinetic models and the achieved respective description of experimental data reveals insights concerning the role of NO-dissociation for the kinetics of Pt-catalyzed ammonia oxidation. The best fit was obtained 

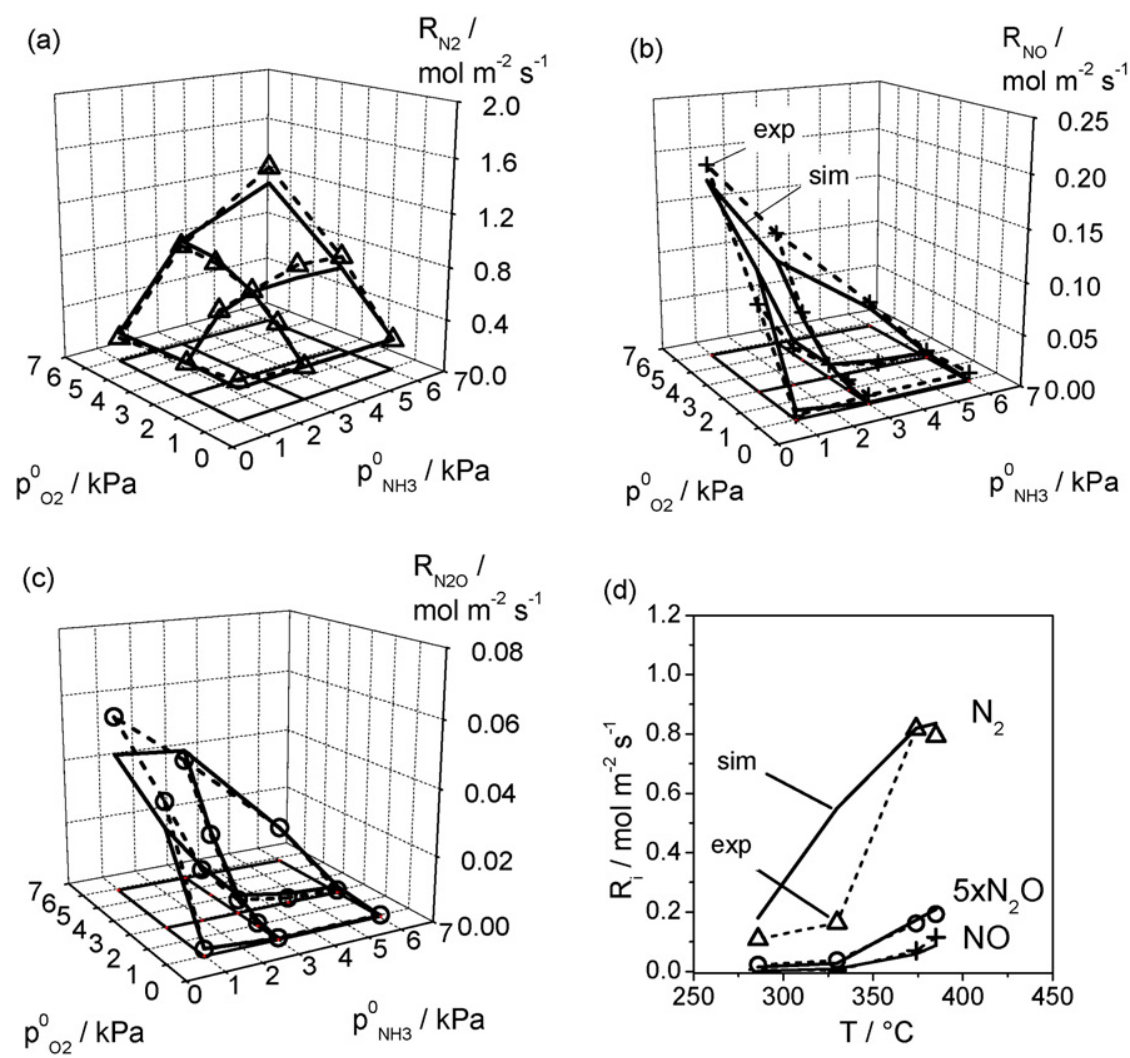

Fig. 11. (a-c) Model C: influence of partial pressure of oxygen and ammonia, experiment vs. simulation. (a) Rate of $\mathrm{N}_{2}$ formation at $385^{\circ} \mathrm{C}$; (b) rate of $\mathrm{NO}$ formation at $385^{\circ} \mathrm{C}$; (c) rate of $\mathrm{N}_{2} \mathrm{O}$ formation at $385^{\circ} \mathrm{C}$; (d) influence of temperature on the rates of formation of $\mathrm{N}_{2}, \mathrm{~N}_{2} \mathrm{O}$ and $\mathrm{NO}$, experiment vs. simulation $\left(p_{\mathrm{NH}_{3}}=3 \mathrm{kPa}\right.$, $\left.p_{\mathrm{O}_{2}}=6 \mathrm{kPa}\right)$.

with model C that, in contrast to models A and B, did not contain the reaction term for NO dissociation $\left(r_{6 r}\right.$ in Tables $\left.1-3\right)$. This, of course, does not allow the conclusion that $\mathrm{NO}$ dissociation is not catalyzed at all by Pt foil; nevertheless, the decomposition of nitric oxide appears to be negligibly slow under the conditions of the present ammonia oxidation experiments.

Different factors may contribute to such a low rate of NO dissociation. Most of all, the oxygen present in the feed competes with NO for adsorption sites, reducing NO coverage on the surface. In addition to a surface site for the adsorption of $\mathrm{NO}$, the NO dissociation requires also empty neighboring sites $[38,39,66,74]$, which can be blocked by adsorbed oxygen as well as $\mathrm{NO}_{\mathrm{ads}}$ or $\mathrm{N}_{\mathrm{ads}}$ under reaction conditions of ammonia oxidation. The deduced low relevance of NO decomposition in the reaction system near atmospheric pressure is in contrast to ammonia oxidation studies under UHV conditions [10,56,57], indicating differences induced by the surface coverage at dif- ferent pressures, a so-called "pressure gap" [19]. Alternatively to the explanation by the effect of high surface coverage, the surface of the studied Pt foil could also resemble the assumed $\operatorname{Pt}\left(\begin{array}{lll}1 & 1 & 1\end{array}\right)$ model surface, a surface plane which is known for its low activity in catalytic decomposition of nitric oxide.

Model C differs from the kinetic models of Scheibe et al. [10] and Rebrov et al. [16] also in another related aspect: it contains an adsorption step for nitric oxide. The experimental data clearly show that $\mathrm{NO}$ inhibits the reaction between ammonia and oxygen, and contributes to $\mathrm{N}_{2} \mathrm{O}$ formation (Fig. 5). Hence, adsorption of NO is an essential part of the kinetic model for the investigated temperature and pressure range.

With respect to the influence of partial pressures of oxygen and ammonia, the experimental data indicated negligible inhibition of rates of product formation in excess of $\mathrm{NH}_{3}$ as well as $\mathrm{O}_{2}$. While models $\mathrm{B}$ and $\mathrm{C}$ (dual site) described the pressure dependence of product formation well, model A (single site) did

Table 4

Discrimination between models B and C, based on lack-of-fit and significance test

\begin{tabular}{|c|c|c|c|c|c|c|c|c|c|}
\hline \multirow[t]{2}{*}{ Product species } & \multicolumn{2}{|c|}{ Degree of freedom of the models } & \multicolumn{2}{|c|}{ Squared sum for lack-of-fit } & \multicolumn{2}{|c|}{ Mean squares for lack-of-fit } & \multirow[t]{2}{*}{$F$-value } & \multirow[t]{2}{*}{$F_{\text {critical }}(\alpha=1 \%)$} & \multirow[t]{2}{*}{ Passing $F$-test? ${ }^{\mathrm{a}}$} \\
\hline & $\mathrm{d} f_{\mathrm{L}, \mathrm{B}}$ & $\mathrm{d} f_{\mathrm{L}, \mathrm{C}}$ & $\mathrm{SS}_{\mathrm{L}, \mathrm{B}}$ & $\mathrm{SS}_{\mathrm{L}, \mathrm{C}}$ & $\mathrm{MS}_{\mathrm{L}, \mathrm{B}}$ & $\mathrm{MS}_{\mathrm{L}, \mathrm{C}}$ & & & \\
\hline$\overline{\mathrm{N}_{2}}$ & 34 & 36 & $6.65 \mathrm{E}-01$ & $3.63 \mathrm{E}-01$ & $1.96 \mathrm{E}-02$ & $1.01 \mathrm{E}-02$ & 1.83 & 2.24 & Yes \\
\hline $\mathrm{N}_{2} \mathrm{O}$ & 34 & 36 & $6.29 \mathrm{E}-05$ & $2.78 \mathrm{E}-05$ & $1.85 \mathrm{E}-06$ & $7.72 \mathrm{E}-07$ & 2.26 & 2.24 & No \\
\hline
\end{tabular}

\footnotetext{
a Assuming the validity of $F$-test prerequisites (normal distributed, independent samples).
} 

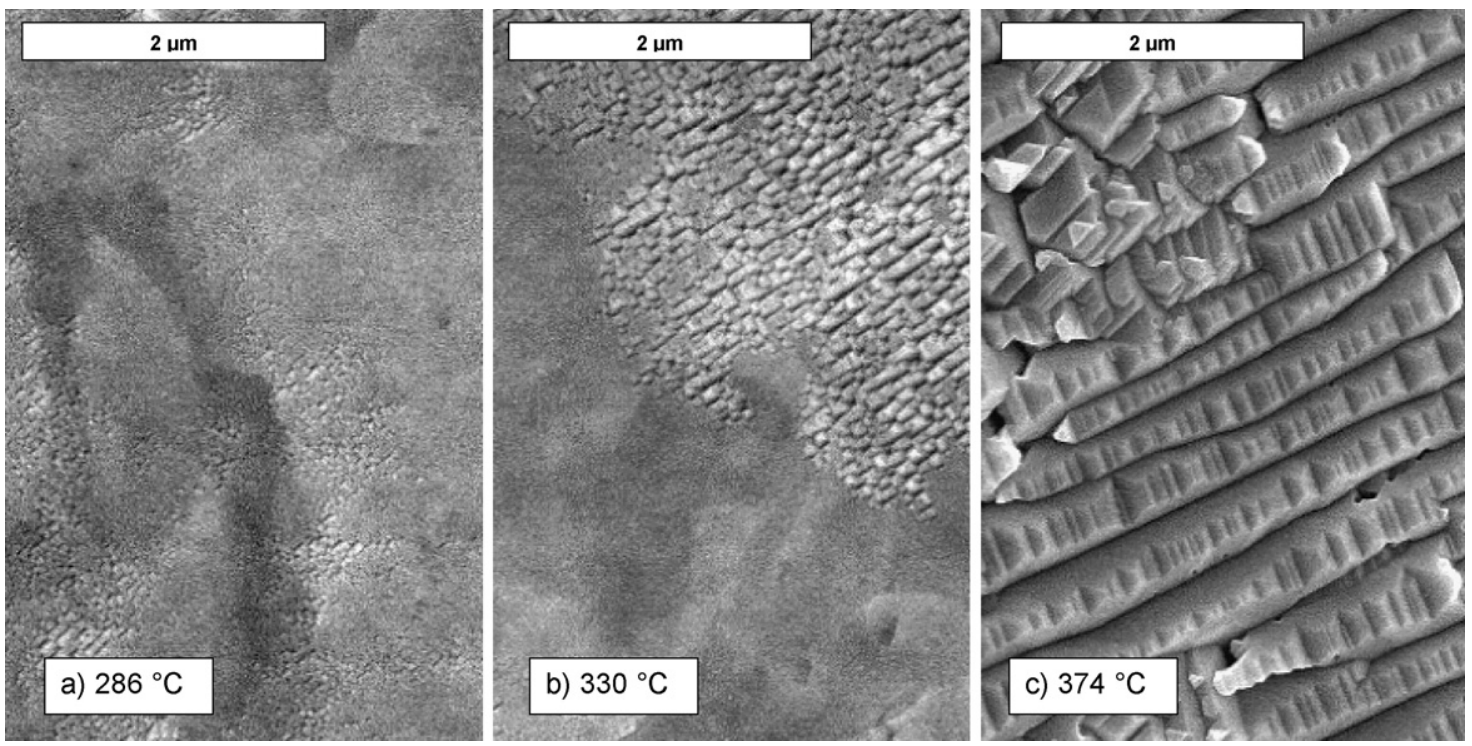

Fig. 12. (a-c) Surface of Pt foil imaged by SEM after applying the catalyst in kinetic measurements of ammonia oxidation at constant temperature of (a) $286^{\circ} \mathrm{C}$, (b) $330^{\circ} \mathrm{C}$ and (c) $374^{\circ} \mathrm{C}$ for about $30 \mathrm{~h}$ time-on-stream.

not account for the absence of inhibition. Hence, the assumption of two energetically different adsorption sites for ammonia and oxygen is reasonable.

Literature values of activation energies are listed in Table 3 along with the values derived for model C. It is evident from the data that all values for adsorption and desorption of the feed molecules (1h, 1r, $2 \mathrm{~h}$ and $2 \mathrm{r}$ ) agree rather well with literature data. Moreover, also the energy barriers for NO desorption (4h) are almost identical. With respect to the activation energy for the lumped reaction step of ammonia activation to form adsorbed nitrogen (3h) the literature data show a wide scatter, with the present value of $99.5 \mathrm{~kJ} / \mathrm{mol}$ being in the range of published data. In contrast, for the reaction steps forming the nitrogen-containing products (5h, $6 \mathrm{~h}$ and $7 \mathrm{~h}$ ) the present model $\mathrm{C}$ computes higher activation energies than previously reported (Table 3). All of the three respective reactions have in common that they convert the nitrogen-containing surface intermediate, $N_{\text {ads }}$. Hence, one possible explanation for the computation of too high $E_{\mathrm{A}}$ values is that the applied assumption of forming $N_{\mathrm{ads}}$ via one lumped reaction step ( $3 \mathrm{~h}$ ) is oversimplified, and cannot predict the actual temperature influence on the surface coverage of nitrogen with sufficient accuracy. In fact, the complete dehydrogenation of ammonia in one step (although being useful) is a rather crude assumption. From a mechanistic point of view the stepwise dehydrogenation of ammonia by adsorbed $\mathrm{O}_{\text {ads }}$ and $\mathrm{OH}_{\text {ads }}$ via $\mathrm{NH}_{2}$ and $\mathrm{NH}$ has been shown by DFT calculations [19] to be the energetically preferred reaction pathway.

Still, the increase in the rate of $\mathrm{N}_{2}$ formation with increasing temperature was not fully described by all tested kinetic models. Therefore, the corresponding values of activation energy, which account for the temperature dependence of reaction kinetics, may be of limited accuracy. The systematic deviation (predicted rates are too high at low temperatures) indicates that a second temperature dependence was possibly superimposed to the Arrhenius law of chemical kinetics. Such a temperature dependence may, for example, be a change in number or nature of active sites with temperature. Experimental rates of product formation were calculated in the present work assuming a constant number of Pt sites, corresponding to the geometric area of a flat $\mathrm{Pt}$ foil surface. This assumption was a necessary simplification, since total surface areas were too low to be measured with the available adsorption techniques.

To verify this assumption of known constant surface area, the catalyst surface was studied by SEM after the kinetic measurements. The respective images are shown in Fig. 12 for the Pt surface after ammonia oxidation at 286,330 and $374{ }^{\circ} \mathrm{C}$, respectively. A comparison between the three images, also to the image of a fresh Pt foil (Fig. 1) indicates that with increasing temperature a progressing restructuring of the catalyst surface was induced. The major part of the reaction-induced surface restructuring is assumed to occur during the initial period of time-on-stream, i.e. the reported initial activation period. While the surface remained basically flat after ammonia oxidation at $286^{\circ} \mathrm{C}$ (Fig. 12a), parts of the catalyst surface were visibly roughened after reaction at $330^{\circ} \mathrm{C}$ (Fig. 12b). In the high-temperature regime, represented by the image taken after reaction at $374{ }^{\circ} \mathrm{C}$ (Fig. 12c), the complete surface became restructured and faceted. Apparent by the roughening, the surface area of the sample shown in Fig. $12 \mathrm{c}\left(374^{\circ} \mathrm{C}\right)$ should be higher than that of the other two samples (Fig. 12a and b). Hence, the assumption of a known surface area is not fully valid, with the error introduced by the assumption into Eq. (1) increasing with increasing temperature. Measuring the number of active sites as a function of temperature, or at least the catalysts surface area, is desirable, but not feasible due to the small surface area of the samples imposed by the reactor design. Moreover, an influence of the type of surface restructuring (forming facets of different activity, steps, kinks) on the intrinsic catalyst activity cannot be excluded, since ammonia oxidation is known to be structure sensitive. Finally, also the assumption of a uniform surface must be questioned, since the Pt samples did not restructure equally in all areas (Fig. 12b). 
An alternative to determining the surface area experimentally would be avoiding surface restructuring and catalyst activation altogether. This is not feasible, since already for the mild conditions applied in the present experiments $\left(286-385^{\circ} \mathrm{C}\right) \mathrm{a}$ significant restructuring of the catalyst surface was induced by ammonia oxidation. Reducing the temperature further to a value where roughening of the Pt surface was negligible (Fig. 12a) would lead to measurements only at temperatures below $300^{\circ} \mathrm{C}$, hence no NO would be formed (Fig. 3d) and the measured kinetic data would thus remain incomplete.

To test the predictive capabilities of the derived kinetic model, the model was used to compute (differential) selectivities of product formation for conditions similar to those of a typical industrial ammonia burner operating in the mid-pressure range $\left(p_{\text {total }}=4\right.$ bar, $10.5 \% \mathrm{NH}_{3}$ in air, $\left.900^{\circ} \mathrm{C}\right)$. Hence, the simulation had to be extrapolated to significantly higher temperatures and pressures than applied in the actual kinetic experiments. The calculated selectivities amounted to $50 \%$ for nitric oxide, $49.5 \%$ for $\mathrm{N}_{2}$ and $0.5 \%$ for the side product nitrous oxide. The values illustrate the correct trends since they predict $\mathrm{NO}$ selectivity to increase with temperature, and only small amounts of nitrous oxide to be formed, although the actual value of NO selectivity is lower than the practically observed $95 \%$. The remaining deviation between simulated and real values in practice may be attributed to using a differential reactor model, to neglected gasphase reactions and mass transfer influences, and to the use of Pt instead of the industrially applied PtRh alloys.

\section{Conclusions}

A best-fitting kinetic model was identified that described ammonia oxidation over polycrystalline $\mathrm{Pt}$ between 286 and $385^{\circ} \mathrm{C}$ and at reactant partial pressures between 1 and $6 \mathrm{kPa}$ better than previously proposed models. It differed from previous models for $\mathrm{Pt}(533)$ and $\mathrm{Pt} / \mathrm{Al}_{2} \mathrm{O}_{3}[10,16]$ in the assignment of adsorption sites on the assumed model surface. The influence of feed composition could only be described by postulating two energetically different adsorption sites. Moreover, fitting quality improved when a site assignment corresponding to $\mathrm{Pt}\left(\begin{array}{lll}1 & 1 & 1\end{array}\right)$ was used, compared to assuming a $\operatorname{Pt}\left(\begin{array}{ll}1 & 0\end{array}\right)$ surface, i.e. adsorbed $\mathrm{O}$, $\mathrm{N}$ and $\mathrm{NO}$ were assigned to different sites (hollow) than $\mathrm{NH}_{3}$ (on-top). In contrast to literature, dissociation of $\mathrm{N}_{2} \mathrm{O}$ and $\mathrm{NO}$ could be neglected, while molecular adsorption of NO had to be considered in the model to account for site blocking and for increased $\mathrm{N}_{2} \mathrm{O}$ formation with increasing partial pressure of NO.

The influence of feed composition was described well by the simulation, but only moderate agreement was obtained for the temperature dependence. The discrepancy was attributed to an experimentally observed temperature-dependent roughening of the Pt surface, i.e. an increase in surface area, that could not be avoided for the given reaction conditions. Such an extensive reaction-induced roughening of a Pt surface during ammonia oxidation at temperatures as low as $330^{\circ} \mathrm{C}$ and emphasizes the need for supplementing kinetic studies by comprehensive catalyst characterization.

An extrapolation of the best kinetic model to reaction conditions typical for a mid-pressure ammonia burner revealed the correct trends in selectivity as compared to industrial practice. Deviations are presumably due to simplifications in the reactor model neglecting processes of heat and mass transfer.

\section{Acknowledgements}

This work was supported by DFGs priority program SPP 1019 "Bridging the gap between real and ideal systems in heterogeneous catalysis". The provision of SEM images by G. Weinberg and R. Schlögl is gratefully acknowledged.

\section{References}

[1] J.J. Ostermaier, J.R. Katzer, W.H. Manogue, J. Catal. 41 (1976) 277.

[2] T. Pignet, L.D. Schmidt, Chem. Eng. Sci. 29 (1974) 1123.

[3] O. Nilsen, A. Kjekshus, H. Fjellvag, Appl. Catal. A: Gen. 207 (2001) 43.

[4] C.W. Nutt, S. Kapur, Nature 220 (1968) 697.

[5] C.W. Nutt, S. Kapur, Nature 224 (1969) 169

[6] T. Pignet, L.D. Schmidt, J. Catal. 40 (1975) 212.

[7] G.A. Papapolymerou, L.D. Schmidt, Langmuir 1 (1985) 488.

[8] A. Scheibe, Doctoral thesis, Gestufte Platineinkristalloberflaechen als Modellsystem fuer die katalytische Ammoniakoxidation mit Sauerstoff, Universitaet Hannover, Hannover, 2003.

[9] A. Scheibe, U. Lins, R. Imbihl, Surf. Sci. 577 (2005) 1.

[10] A. Scheibe, M. Hinz, R. Imbihl, Surf. Sci. 576 (2005) 131.

[11] N.I. Ilchenko, G.I. Golodets, J. Catal. 39 (1975) 73.

[12] N.I. Ilchenko, V.M. Vorotyntsev, I.M. Avilova, Kinetika Kataliz 17 (1976) 378.

[13] J.J. Ostermaier, J.R. Katzer, W.H. Manogue, J. Catal. 33 (1974) 457.

[14] E.V. Rebrov, M.H.J.M. de Croon, J.C. Schouten, Catal. Today 69 (2001) 183.

[15] E.V. Rebrov, M.H.J.M. de Croon, J.C. Schouten, Chem. Eng. J. 90 (2002) 61.

[16] E.V. Rebrov, M.H.J.M.d. Croon, J.C. Schouten, Chem. Eng. Res. Design 81 (2003) 744.

[17] D.P. Sobczyk, Doctoral thesis, Positron Emission Profiling Study of Ammonia Oxidation on Platinum, Technische Universiteit Eindhoven, Eindhoven, 2003, p. 123.

[18] A.C.M. van den Broek, Doctoral thesis, Low Temperature Oxidation of Ammonia over Platinum and Iridium Catalysts, Technische Universiteit Eindhoven, Eindhoven, 1998.

[19] M. Baerns, R. Imbihl, V.A. Kondratenko, R. Kraehnert, W.K. Offermans, R.A. van Santen, A. Scheibe, J. Catal. 232 (2005) 226.

[20] N. Dropka, K. Jähnisch, E.V. Kondratenko, V.A. Kondratenko, R. Kraehnert, N. Steinfeldt, D. Wolf, M. Baerns, Int. J. Chem. Reactor Eng. 3 (2005) 51.

[21] R. Kraehnert, Doctoral thesis, Ammonia Oxidation over Polycrystalline Platinum: Surface Morphology and Kinetics at Atmospheric Pressure, Technical University of Berlin, Berlin, 2005, pp. 115 and 160.

[22] G.F. Froment, K.B. Bischoff, Chemical Reactor Analysis and Design, John Wiley and Sons, 1990.

[23] D.M. Bates, D.F. Watts, Nonlinear regression analysis and its application, John Wiley \& Sons Inc., New York, 1988.

[24] M. Marsili, Experimental design, in: J. Gasteiger (Ed.), Handbook of Chemoinformatics, Wiley-VCH Verlag, Weinheim, 2003, p. 423.

[25] D. Wolf, R. Moros, Chem. Eng. Sci. 52 (1997) 1189.

[26] J.C. Lagarias, J.A. Reeds, M.H. Wright, M.P. Wright, SIAM J. Optim. 9 (1998) 112.

[27] G.E.P. Box, N.R. Draper, Empirical Model-Building and Response Surfaces, John Wiley \& Sons Inc., New York, 1987.

[28] W.H. Press, S.A. Teukolsky, W.T. Vetterling, B.P. Flammery, Numerical Recipies in Fortran 77, Cambridge University Press, Cambridge, 1991.

[29] N.A.G. Ltd., NAG Fortran Library-Mark 16, 1994.

[30] J.L. Gland, V.N. Korchak, J. Catal. 53 (1978) 9.

[31] A. Scheibe, S. Gunther, R. Imbihl, Catal. Lett. 86 (2003) 33. 
[32] J. Pérez-Ramírez, E.V. Kondratenko, V.A. Kondratenko, M. Baerns, J. Catal. 227 (2004) 90.

[33] V. Kondratenko, Doctoral thesis, Mechanistic Aspects of the PlatinumCatalysed Ammonia Oxidation, Humboldt Universitaet Berlin, Berlin, 2005.

[34] M.H. Kim, J.R. Ebner, R.M. Friedman, M.A. Vannice, J. Catal. 204 (2001) 348-357.

[35] R. Burch, G.A. Attar, S.T. Daniells, D.J. Jenkin, J.P. Breen, P. Hu, Chem. Commun. (2002) 2738.

[36] R. Burch, S.T. Daniells, J.P. Breen, P. Hu, J. Catal. 224 (2004) 252.

[37] R.J. Gorte, L.D. Schmidt, J.L. Gland, Surf. Sci. 109 (1981) 367.

[38] D.C. Skelton, H. Wang, R.G. Tobin, D.K. Lambert, C.L. DiMaggio, G.B. Fisher, J. Phys. Chem. B 105 (2001) 204.

[39] T. Sugisawa, J. Shiraishi, D. Machihara, K. Irokawa, H. Miki, C. Kodama, T. Kuriyama, T. Kubo, H. Nozoye, Appl. Surf. Sci. 169/170 (2001) 292.

[40] H. Wang, R.G. Tobin, C.L. DiMaggio, G.B. Fisher, D.K. Lambert, J. Chem. Phys. 107 (1997) 9569.

[41] T. Katona, L. Guczi, G.A. Somorjai, J. Catal. 135 (1992) 434.

[42] B.A. Sexton, G.E. Mitchell, Surf. Sci. 99 (1980) 523.

[43] M. Garcia-Hernandez, N. Lopez, I.d.P.R. Moreira, J.C. Paniagua, F. Illas, Surf. Sci. 430 (1999) 18.

[44] F. Illas, N. Lopez, M. Garcia-Hernandez, I.d.P.R. Moreira, J. Mol. Struct. (Theochem.) 458 (1999).

[45] D.R. Jennison, P.A. Schultz, M.P. Sears, Surf. Sci. 368 (1996) 253.

[46] J.M. Gohndrone, C.W. Olsen, A.L. Backman, T.R. Gow, E. Yagasaki, R.I. Masel, J. Vac. Sci. Technol. A 7 (1986) 1986.

[47] J.M. Bradley, A. Hopkinson, D.A. King, Surf. Sci. 371 (1997) 255.

[48] Y.K. Park, P. Aghalayam, D.G. Vlachos, J. Phys. Chem. A 103 (1999) 8101.

[49] A. Johansson, M. Foersth, A. Rosen, Surf. Sci. 529 (2003) 247.

[50] S. Ljungstroem, B. Kasemo, A. Rosen, T. Whanstroem, E. Fridell, Surf. Sci. 216 (1989) 63.

[51] C.T. Campbell, G. Ertl, H. Kuipers, J. Segner, Surf. Sci. 107 (1981) 220.

[52] S. Helveg, H.T. Lorensen, S. Horch, E. Laegsgaard, I. Stensgaard, K.W. Jacobsen, J.K. Norskov, F. Besenbacher, Surf. Sci. 430 (1999) L533.
[53] D.I. Jerdev, J. Kim, M. Batzill, B.E. Koel, Surf. Sci. 498 (2002) L91.

[54] W.L. Guthrie, J.D. Sokol, G.A. Somorjai, Surf. Sci. 109 (1981) 390.

[55] D.G. Löffler, L.D. Schmidt, Surf. Sci. 59 (1976) 195.

[56] J.M. Bradley, A. Hopkinson, D.A. King, J. Phys. Chem. 99 (1995) 17032 .

[57] W.D. Mieher, W. Ho, Surf. Sci. 322 (1995) 151

[58] D.P. Sobczyk, A.M. de Jong, E.J.M. Hensen, R.A. van Santen, J. Catal. 219 (2003) 156.

[59] D.P. Sobczyk, J. van Grondelle, P.C. Thüne, I.E. Kieft, A.M. de Jong, R.A. van Santen, J. Catal. 225 (2004) 466.

[60] A.C.M. van den Broek, J. van Grondelle, R.A. van Santen, J. Catal. 185 (1999) 297.

[61] W.K. Offermans, A.P.J. Jansen, R.A. van Santen, Surf. Sci. 600 (2006) 1714.

[62] S.J. Lombardo, M. Slinko, T. Fink, T. Loeher, H.H. Madden, F. Esch, R. Imbihl, G. Ertl, Surf. Sci. 269/270 (1992) 481.

[63] M.F.H.v. Tol, J. Siera, P.D. Cobden, B.E. Nieuwenhuys, Surf. Sci. 274 (1992) 63.

[64] A. Bogicevic, K.C. Hass, Surf. Sci. 506 (2002) L237.

[65] S.B. Lee, D.H. Kang, C.Y. Park, H.T. Kwak, Bull. Korean Chem. Soc. 16 (1995) 157.

[66] R.J. Mukerji, A.S. Bolina, W.A. Brown, J. Chem. Phys. 119 (2003) 10844.

[67] K. Otto, M. Shelef, J.T. Kummer, J. Phys. Chem. 74 (1970) 2690.

[68] M. Kim, D.A. King, S.J. Pratt, J. Am. Chem. Soc. 122 (2000) 2409.

[69] M.Y. Smirnov, V.V. Gorodetskii, J.H. Block, J. Mol. Catal. A: Chem. 107 (1996) 359.

[70] M. Rinnemo, O. Deutschmann, F. Behrendt, B. Kasemo, Combust. Flame 111 (1997) 312

[71] A.T. Gee, B.E. Hayden, J. Chem. Phys. 113 (2000) 10333.

[72] J.F. Zhu, M. Kinne, T. Fuhrmann, R. Denecke, H.P. Steinrück, Surf. Sci. 529 (2003) 384.

[73] J.F. Zhu, M. Kinne, T. Fuhrmann, B. Tränkenschuh, R. Denecke, H.P. Steinrück, Surf. Sci. 547 (2003) 410.

[74] R.J. Mukerji, A.S. Bolina, W.A. Bronw, Surf. Sci. 547 (2003) 27. 